\title{
Minería y seguridad hídrica en el noroeste de México: un análisis de doble exposición
}

\author{
Mining and Water Security in Northwestern Mexico: \\ A Double Exposure Approach
}

\author{
América Nallely Lutz Ley* (D) https://orcid.org/0000-0002-7257-616X
}

\begin{abstract}
Resumen
El objetivo es explorar las relaciones entre la minería y la seguridad hídrica en Sonora en un contexto de cambio climático, y cómo éstas colocan a las comunidades rurales en una situación de doble exposición. La localidad de Cucurpe sirve para ejemplificar dichas relaciones. Se integran técnicas cuantitativas y cualitativas de recolección, construcción y análisis de datos espaciales, estadísticos y de discurso en varias escalas. Los hallazgos indican que gran parte de las concesiones mineras de tierra y agua están en zonas con importantes limitaciones hídricas. Aunque localmente existen beneficios, las comunidades asumen riesgos inciertos que no pueden prever en el corto plazo. El estudio tiene limitaciones relacionadas con su carácter exploratorio y descriptivo, que podrían mejorarse en el futuro con muestras de estudio representativas a nivel regional. Se concluye señalando la importancia de la colaboración entre los sectores minero, gubernamental y social para lograr la seguridad hídrica frente al cambio climático.

Palabras clave: minería a gran escala; seguridad hídrica; doble exposición; comunidades rurales; noroeste de México.
\end{abstract}

\begin{abstract}
This study's objective is to explore the relationship between mining and water security in a climate change context in Sonora, and how this put rural communities in a situation of double exposure. These relationship examples belong to the locality of Cucurpe. Methodology integrates quantitative and qualitative techniques for collecting, constructing, and analyzing spatial, statistical, and discursive data at various scales. Findings indicate that a majority of the land and water mining concessions are located in zones with important water limitations. Although locally there are benefits, communities take uncertain risks not fully foreseeable in the short term. The study has limitations related to its exploratory and descriptive nature, which could be better addressed in future studies with samples more representative regionally. The conclusions point out the importance of inter-sectoral collaborations between mining, the government, and society, to achieve water security in face of climate change. Keywords: large scale mining; water security; double exposure; rural communities; northwest Mexico.
\end{abstract}

Lutz Ley,A. N. (2020). Minería y seguridad hídrica en el noroeste de México: un análisis de doble exposición. región y sociedad, 32 , el 295. doi: I0.22198/rys2020/32/I295

* El Colegio de Sonora. Centro de Estudios del Desarrollo. Ave. Álvaro Obregón Núm. 54, Colonia Centro, C. P. 83000, Hermosillo, Sonora, México. Correo electrónico: alutz@colson.edu.mx

Recibido: 24 de enero de 2020

Aceptado: 28 de mayo de 2020

Liberado: 25 de junio de 2020 \\ 4.0 Internacional.




\section{Introducción}

El noroeste árido de México es un foco rojo del cambio climático. Se proyecta que la región tendrá temperaturas más altas y precipitación más variable con reducciones significativas entre mediados y finales de este siglo (Magaña, 2006), lo cual afectará los volúmenes de los escurrimientos y la disponibilidad regional de agua para uso humano (Overpeck et al., 2013). Los cambios mencionados afectarán de manera particular los hogares dependientes de los recursos naturales, porque reducirán la disponibilidad y la variedad de sus medios de vida (actividades y recursos para el sustento, como la agricultura y la ganadería) debido a su escasez o, de forma indirecta, a través de los cambios en la temporalidad y los patrones de ocurrencia (por ejemplo, ciclos hidrológicos alterados) (Agrawal y Perrin, 2008).

Uno de estos medios de vida es la minería, que se practica en gran parte del territorio sonorense a la par de medios de vida agropecuarios. A lo largo de la historia, la minería ha sido importante para Sonora por la producción de materiales industriales (como el cobre) y de metales preciosos para el comercio internacional (oro y plata) (Bracamonte, Lara y Borbón, 1997). Sonora ocupa el primer lugar nacional en producción de oro, cobre, molibdeno, grafito y wollastonita, y es el único productor nacional de los tres últimos (Servicio Geológico Mexicano [SGM], 2017).

La actividad minera, a través de sus efectos socioeconómicos y ambientales, conecta distintas escalas del sistema socio-ecológico de las cuencas hidrológicas. En primer lugar, causa un impacto socioeconómico mixto en las comunidades, pues representa una alternativa económica a los medios de vida agropecuarios. En condiciones de pobreza y marginación, cuando no todos los hogares tienen acceso a recursos primarios (tierra, agua, animales), la minería provee empleos a los habitantes rurales con salarios relativamente altos considerando su nivel educativo promedio y los otros trabajos disponibles en la localidad (Lutz y Buechler, 2020).

Sin embargo, el trabajo minero varía porque depende del valor de los minerales en el mercado, en particular desde que la minería sonorense comenzó a tener mayores proporciones de inversión extranjera y una producción más orientada hacia el mercado internacional (Bracamonte et al., 1997). Debido a lo anterior, las empresas mineras tienen fluctuaciones ligadas a las dinámicas globales, lo que afecta la continuidad del empleo. Además, las empresas de corta vida tienen una alta tasa de subcontratación que no brinda seguridad ni puestos base para sus empleados. Aunque la minería ha creado empleos, éstos tienden a ser precarios debido a las fluctuaciones en los mercados globales y la alta tasa de subcontratación en el sector (Lutz y Buechler, 2020).

Con respecto a los impactos ambientales, en México no existen estudios sistemáticos longitudinales que demuestren los efectos de la minería sobre las diferentes escalas de funcionamiento de los ecosistemas y de los recursos naturales de las cuencas. La sociedad tampoco es consciente de estos efectos sino hasta que ocurre un desastre. En general, pueden observarse dos tipos de afectaciones ambientales: por un lado, están los impactos puntuales, por lo común 
evidentes, como la contaminación por derrames de las presas de jales y los derrumbes ocasionados por el cambio en la estructura del suelo, entre otros; por el otro lado, están los efectos observables a largo plazo, tales como la contaminación del aire, la extracción, el agotamiento y la contaminación progresiva de agua y suelo y la emisión de gases de efecto invernadero (GEI) (Aburto, Rojo y Ezcurra, 2015; Romero, Armienta, Gutiérrez y Villaseñor, 2008). La mayoría de los estudios que relacionan la minería con el cambio climático se enfocan en el sector minero como emisor de GEI. Un problema que ha sido menos analizado es cómo el cambio climático afectará al sector minero, particularmente en el noroeste árido y semiárido de México y cómo estas afectaciones climáticas se combinan con los efectos propios de la minería para generar nuevos estresores sobre los recursos hídricos de las comunidades rurales ubicadas alrededor de esos puntos mineros.

Tratando de responder a esta brecha, el presente estudio explora las relaciones entre el cambio climático, la minería a gran escala y la seguridad hídrica de las comunidades rurales sonorenses con presencia minera. En particular, el objetivo es indagar cómo el cambio climático impacta en el sector minero sonorense, cómo responde el sector ante dichos impactos y cómo esto, a su vez, puede generar efectos en cascada que impacten la seguridad hídrica de las comunidades rurales mineras. Se define seguridad hídrica como "la disponibilidad sustentable de agua en cantidad y calidad suficiente para sociedades y ecosistemas resilientes frente al cambio global incierto" (Scott et al., 2013, p. 281). De este modo, las comunidades rurales y su seguridad hídrica podrían verse en una situación de doble exposición, es decir, ante el cambio climático que se combina con la minería a gran escala (Leichenko y O'Brien, 2008).

El acercamiento a estas dinámicas se desarrolló desde un enfoque mixto en tres fases combinando métodos cuantitativos y cualitativos para la recolección, la construcción y el análisis de datos. Primero, mediante el análisis espacial a escala estatal, se exploran los indicadores de seguridad hídrica en relación con la minería. Segundo, mediante el análisis estadístico de respuestas a una encuesta, se identifican los efectos percibidos del cambio y la variabilidad climáticos sobre la minería y las estrategias de adaptación reportadas por representantes del sector minero estatal. Por último, se abordó el caso de Cucurpe, comunidad rural con presencia minera en el centro-norte de Sonora, para ejemplificar estas dinámicas a escala local, mediante entrevistas a los habitantes acerca de los efectos combinados de la minería y el cambio climático sobre la comunidad y sus recursos.

\section{Minería rural, seguridad hídrica y cambio climático}

El planeta atraviesa por un proceso de calentamiento global cuyas manifestaciones más generalizadas son el incremento de la temperatura, mayor variabilidad hidro-climática e incrementos en el nivel promedio del mar (Intergovernmental Panel on Climate Change [IPCC], 2014). En el noroeste de México, varios investigadores han encontrado evidencias empíricas de calentamiento a 
nivel regional. Por ejemplo, Martínez-Austria, Patiño-Gómez y Tamayo-Escobar (2014) analizaron las tendencias climáticas de la cuenca baja del río Yaqui, en el sur de Sonora, entre 1949 y 2011, y al comparar las diferencias entre temperaturas mínimas y máximas, observaron una reducción significativa, más acentuada en las últimas décadas, lo cual indica una tendencia al calentamiento. Los autores también analizaron la precipitación en este periodo sin observar ninguna tendencia clara. En coincidencia con esto, Mateos, Santana, Montero-Martínez, Deeb y Grunwaldt (2016), al evaluar evidencias de cambio climático en diez cuencas de México de 1970 a 2009, incluida la del río Yaqui, identificaron una tendencia incremental en la temperatura, aunque para la precipitación no encontraron un patrón definido.

Mientras que en esos estudios evaluar los cambios en la precipitación se dificulta debido a la influencia de los factores regionales y locales sobre la lluvia (Mateos et al., 2016), prácticamente todos los estudios climáticos del noroeste de México reportan una tendencia creciente en la temperatura. Por ejemplo, Martínez-Austria, Bandala y Patiño-Gómez (2016), al analizar datos de las estaciones climáticas entre 1960 y 2010, encontraron una tendencia positiva tanto en la temperatura como en la frecuencia de ondas de calor en Sonora y Baja California, estados que, según los autores, se espera que muestren los incrementos de temperatura más altos en el trascurso de este siglo en México. Navarro-Estupiñán, Robles Morua, Vivoni, Zepeda, Montoya y Verduzco (2018) lo confirman. Ellos, utilizando información de temperaturas máximas de aire en 27 estaciones climatológicas en Sonora entre 1966 y 2015, encontraron una tendencia positiva y significativa en 24 de ellas. Los datos locales también se han empleado para la regionalización (downscaling) de distintos acoplamientos de los modelos de circulación global (GCM por sus siglas en inglés) ajustados al noroeste de México para proyectar cambios futuros en la temperatura y en la precipitación. Proyecciones de este tipo realizadas por Montero-Martínez, Martínez-Jiménez, Castillo-Pérez y Espinoza-Tamarindo (2010), utilizando información de 23 GCM del Cuarto Reporte de Evaluación del IPCC (2014), indican que entre mediados y finales del presente siglo (2060-2090) la lluvia en Sonora se reduciría en alrededor de $29 \%$ en invierno y $20 \%$ en verano. En términos del cambio de temperaturas para ese mismo periodo, los autores estimaron un incremento en las temperaturas promedio de 3.3 grados Celsius en invierno y 3.59 grados Celsius en verano. Estas proyecciones son importantes para informar impactos potenciales sobre los recursos hídricos del estado y sobre su disponibilidad para las actividades productivas, incluidas la minería a gran escala y la agricultura en comunidades rurales.

Monge, Patzy y Viale (2013) señalan que no existen estudios regionales del efecto de la actividad minera sobre el consumo y la calidad del agua en un contexto de cambio climático, pero podría esperarse que éste agudice la escasez y el conflicto por el agua entre los usuarios mineros y rurales de zonas áridas y semiáridas del noroeste de México. Según sus estimaciones, hasta 2013 la minería en México utilizaba aproximadamente 2.9 metros cúbicos por segundo $\left(\mathrm{m}^{3} / \mathrm{s}\right)$ o casi 91.5 millones de metros cúbicos por año $\left(\mathrm{Mm}^{3} /\right.$ año) de agua. Sin embargo, como plantean los autores, no hay información que permita determinar qué tan 
confiables son estas estimaciones. De cualquier manera, aunque globalmente la minería no representa un porcentaje muy alto del volumen total del recurso hídrico para uso humano, señalan que sí es uno de los sectores que más rápido han crecido en México y América Latina.

En 2016, CartoCrítica y Heinrich Böll Stiftung publicaron un estudio sobre el agua en el sector minero mexicano y especificaron que esa industria tenía 1036 títulos de concesión equivalentes a $437 \mathrm{Mm}^{3} /$ año distribuidos entre 417 empresas. Esto era suficiente para cubrir la demanda promedio de aproximadamente 3.2 millones de mexicanos. La mitad del volumen total concesionado para la minería se extrajo en tres estados: Sonora (202 títulos, $107.9 \mathrm{Mm}^{3}$ / año), Zacatecas (98 títulos, $55.8 \mathrm{Mm}^{3} /$ año) y Michoacán (9 títulos, $44.4 \mathrm{Mm}^{3}$ / año). Los hallazgos deben tomarse con reserva, ya que existe gran opacidad en los datos del sector minero: hay dificultades para identificar a los usuarios y sus volúmenes asignados en el Registro Público de Derechos de Agua (REPDA), los estándares para el tratamiento de la información son irregulares y faltan reportes sistemáticos y actualizados del consumo.

El consumo intensivo de recursos hídricos por parte del sector minero, combinado con los efectos del cambio climático sobre las temperaturas y el ciclo hidrológico (reducción de disponibilidad y calidad de agua en el mediano y largo plazo), pueden provocar problemas de competencia por el agua entre la minería y las comunidades rurales. Otros investigadores han argumentado que la inequidad en la distribución de recursos (y no el daño ambiental per se) es lo que acelera o profundiza los conflictos asociados con la minería (Kotsadam y Tolonen, 2016; Loayza y Rigolini, 2016; Yacoub y Boelens, 2015). Los conflictos por la distribución y el uso inequitativo del agua entre sectores podrían potenciarse en estas condiciones. A pesar de la importancia del tema en Sonora, no existen diagnósticos sistemáticos que relacionen la minería con la seguridad hídrica en las comunidades rurales en un contexto de cambio climático.

\section{Marco de doble exposición (MDE)}

Las comunidades rurales no sólo están expuestas a los estresores asociados con el cambio climático. Las localidades de todo el mundo, en mayor o menor grado, se encuentran expuestas a lo que Leichenko y O'Brien (2008) han llamado doble exposición. Esto se refiere a que los procesos de cambio climático se combinan con cambios socioeconómicos y culturales asociados con la globalización. Estos procesos combinados tienen distintos efectos a escala local. En un sentido negativo, pueden incrementar la vulnerabilidad de las comunidades, reducir sus capacidades adaptativas, degradar su medio ambiente, incrementar la inseguridad de sus recursos y disminuir su calidad de vida en general. En el largo plazo pueden incrementar las inequidades económicas y polarizar a la sociedad, lo cual disminuye la resiliencia del sistema socio-ecológico global (es decir, que éste se vuelve menos apto para resistir crisis futuras).

Estos procesos combinados también pueden abrir nuevas oportunidades para distintos grupos sociales, tales como un mejor acceso a productos y servicios, 
mayores niveles educativos, mejor interconexión con el mundo, oportunidades para fortalecer el respeto a los derechos humanos y compartir conocimientos y recursos para mejorar la adaptación. La idea subyacente es que, debido a la complejidad de los procesos de cambio global, los impactos, las respuestas y los resultados finales de estos procesos varían mucho de un lugar a otro y generan “ganadores" y “perdedores" (Leichenko y O'Brien, 2008). El MDE tiene seis componentes analíticos que guían este análisis (véase figura 1):

Figura 1. Marco de doble exposición

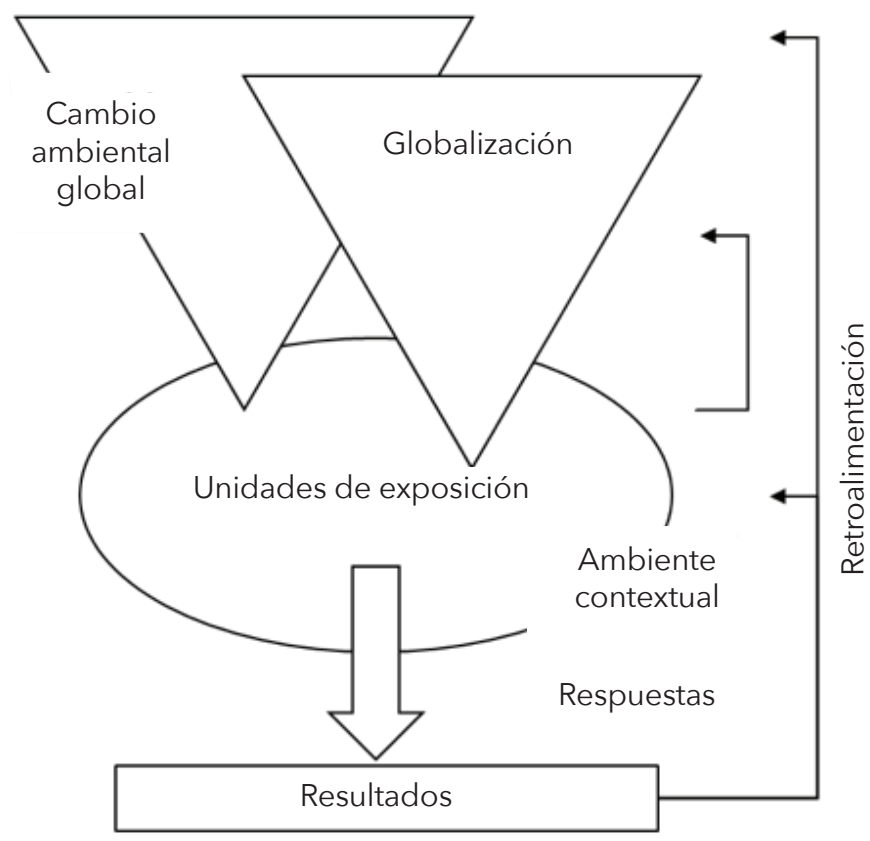

Fuente: Leichenko y O’Brien (2008, p. 39). Traducción propia.

1. Los procesos globales aparecen en la figura 1 desagregados como cambio ambiental global (cambio climático) y los cambios socioeconómicos y culturales asociados con la globalización. Ambos procesos generan estresores (afectaciones progresivas) e impactos súbitos (shocks). En el caso de las comunidades rurales sonorenses, los procesos globales se manifestarían como cambios en los parámetros ambientales locales y como trasformaciones socioeconómicas derivadas de la integración de estas comunidades a cadenas de valor global a través de la minería y otras actividades.

2. El marco de exposición (el óvalo en la figura 1) se refiere a la delimitación geográfica, social, política o ecológica del espacio afectado por las dobles exposiciones. Las unidades de exposición son los elementos sociales y ecológicos de este marco que enfrentan estresores y shocks. En este caso, el 
marco de exposición en un primer momento es el estado de Sonora con sus cuencas hidrológicas y las minas como unidades de exposición. En un segundo momento, la localidad de Cucurpe y sus hogares (el marco y las unidades de exposición, respectivamente) se presentan para ejemplificar estas dinámicas.

3. El ambiente contextual es el conjunto de condiciones sociales, económicas, biofísicas, tecnológicas, institucionales, políticas y culturales que influyen en el nivel de exposición y condicionan las respuestas que el marco y la unidad o las unidades de exposición desempeñan frente a estresores y shocks. Algunas de estas condiciones actuarán como barreras a la adaptación o como elementos que incrementan la vulnerabilidad o como facilitadores cuando incrementan la capacidad de responder y adaptarse. Aquí son importantes los marcos institucionales que regulan el acceso y la distribución de medios de producción rurales, como la tierra y el agua.

4. El conjunto de respuestas incluye todas las decisiones, comportamientos o políticas desarrolladas por cualquiera de las unidades expuestas con el objetivo de mitigar, enfrentar o adaptarse a los efectos de los procesos globales. En este trabajo se recopilan las respuestas de adaptación de la industria minera frente a los impactos percibidos del cambio climático, así como las de los miembros de los hogares frente a los potenciales efectos combinados de la minería y el cambio climático.

5. Los resultados son los efectos medibles u observables de la interacción entre el o los estresores y shocks y los impactos surgidos de los procesos globales y las respuestas ante éstos.

6. La retroalimentación se constituye en conexiones interactivas entre los elementos del modelo. Mediante estos ciclos de retroalimentación, eventos o características dinámicas de un componente pueden volverse promotores de eventos, o resultados de otros componentes a través de distintas escalas espaciales o temporales.

En un primer momento del estudio se analizan los indicadores de seguridad hídrica relacionados con la minería a escala estatal. Después se identifican los efectos percibidos del cambio climático sobre la actividad minera en Sonora de acuerdo con los reportes de representantes del sector (véase la letra a de la figura 2). Al final, se retoman los efectos de la interacción entre minería y cambio climático y se proyectan como retroalimentación (efectos cascada), utilizando como ejemplo el caso de Cucurpe, una comunidad rural con presencia minera ubicada en la parte alta de la cuenca del río San Miguel, para observar cómo los impactos de la minería, aunados a los impactos del cambio climático, afectan a la localidad y cómo los habitantes responden a estos estresores y shocks (véase la letra b de la figura 2). 


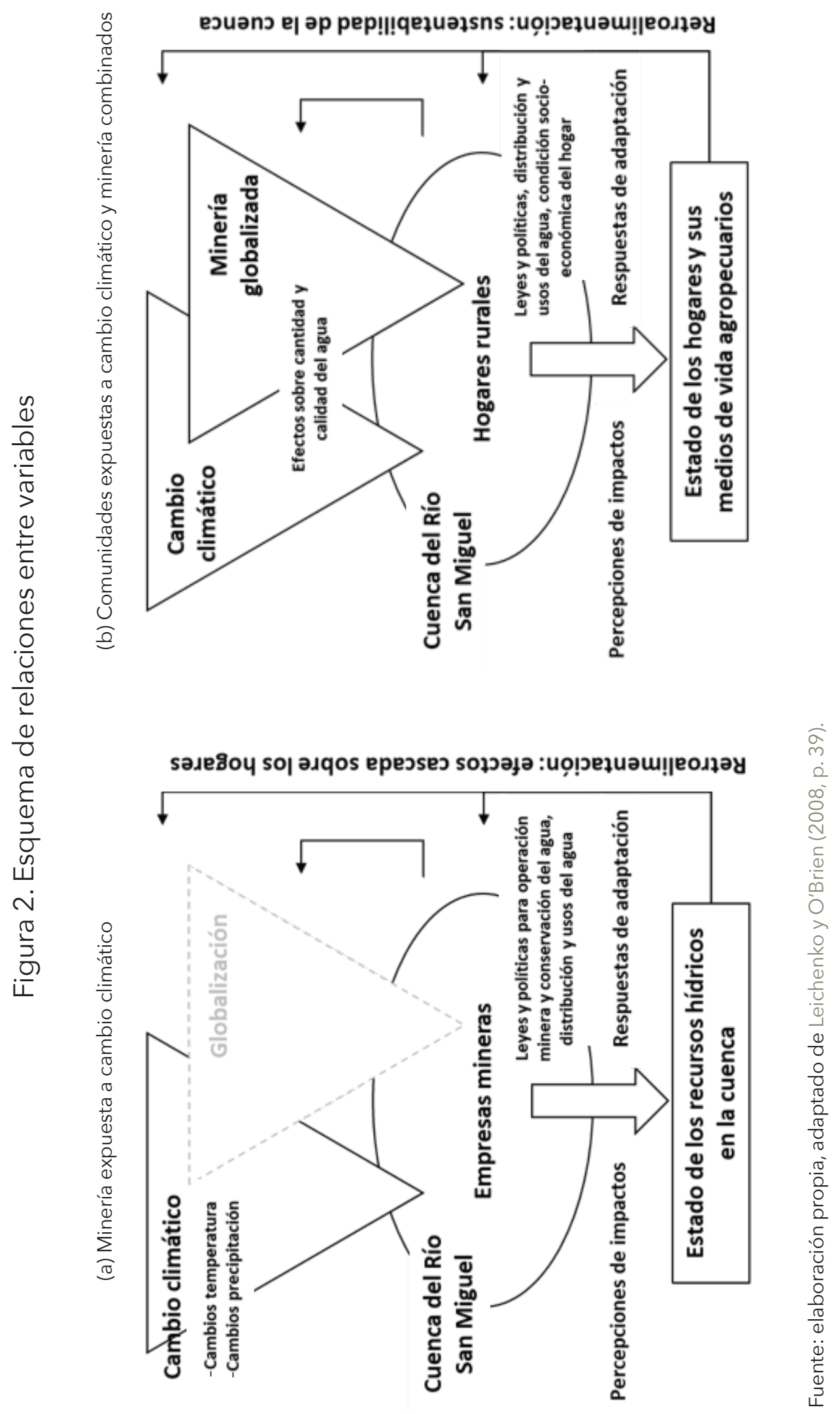




\section{Métodos y procedimientos}

Indicadores de seguridad hídrica y de minería en Sonora

En la primera fase se analizó la información estadística y espacial sobre las concesiones mineras en Sonora hasta 2015, las unidades mineras activas a diciembre de 2017, los permisos de aguas nacionales otorgados a compañías mineras hasta agosto de 2019 y los indicadores de disponibilidad en los acuíferos y cuencas hasta 2015 (véase tabla 1). Esto permitió caracterizar el contexto hidrológico en el que se encuentran las minas y las comunidades rurales del estado. También permitió describir los potenciales estresores y los shocks para minas y comunidades derivados del estatus hídrico de las cuencas donde éstas se ubican.

Tabla 1. Datos y métodos de la primera fase

\begin{tabular}{|c|c|c|}
\hline Indicadores & Recolección & Análisis \\
\hline $\begin{array}{c}\text { Número y localización de minas } \\
\text { de minerales metálicos } \\
\text { y no metálicos activas hasta } \\
\text { diciembre de } 2017\end{array}$ & $\begin{array}{c}\text { Portales web del Servicio } \\
\text { Geológico Mexicano (SGM) } \\
\text { y la Secretaría de Economía, } \\
\text { Dirección de Minas }\end{array}$ & $\begin{array}{l}\text { Mapeo en ArcGIS } \\
\text { y estadística descriptiva } \\
\text { de los indicadores }\end{array}$ \\
\hline \multicolumn{2}{|c|}{$\begin{array}{c}\text { Superficie terrestre concesionada para fines } \\
\text { de exploración y/o explotación minera hasta } 2015 \\
\text { Base de datos en línea de la Secretaría de Economía, } \\
\text { Dirección de Minas }\end{array}$} & $\begin{array}{l}\text { Mapeo en ArcGIS } \\
\text { y estadística descriptiva } \\
\text { de los indicadores }\end{array}$ \\
\hline $\begin{array}{l}\text { Permisos de agua registrados } \\
\text { en REPDA para el sector minero } \\
\text { en Sonora hasta diciembre de } \\
2014 \text { (CartoCrítica y Heinrich } \\
\text { Böll Stiftung para México, } \\
\text { Latinoamérica y el Caribe, 2016) }\end{array}$ & $\begin{array}{c}\text { Base de datos de } \\
\text { CartoCríticaorg y Heinrich } \\
\text { Böll Stiftung para México, } \\
\text { Latinoamérica y el Caribe } \\
\text { (2016) }\end{array}$ & \multirow{2}{*}{$\begin{array}{c}\text { - Triangulación entre registros } \\
\text { de minas activas reportadas por } \\
\text { el SGM, CartoCrítica y Heinrich } \\
\text { Böll (2016) y REPDA (Comisión } \\
\text { Nacional del Agua } \\
\text { [CONAGUA], 2019) } \\
\text { - Ubicación de minas comunes } \\
\text { a los tres registros y captura de } \\
\text { volúmenes de concesión } \\
\text { - Geolocalización de puntos de } \\
\text { extracción de agua para minería } \\
\text { en Google Earth para posterior } \\
\text { importación en ArcGIS }\end{array}$} \\
\hline $\begin{array}{l}\text { Permisos de agua registrados } \\
\text { en REPDA para el sector } \\
\text { minero en Sonora hasta agosto } \\
\text { de } 2019 \text { (CONAGUA, 2019) }\end{array}$ & $\begin{array}{l}\text { Base de datos en línea } \\
\text { del REPDA } \\
\text { (CONAGUA, 2019) }\end{array}$ & \\
\hline $\begin{array}{l}\text { Situación de los acuíferos } \\
\text { de Sonora hasta diciembre } \\
\text { de } 2015\end{array}$ & \begin{tabular}{|} 
Obtención de información \\
espacial de estatus de \\
disponibilidad de acuíferos en \\
el portal de datos del \\
gobierno federal \\
(CONAGUA, 2015a)
\end{tabular} & $\begin{array}{l}\text { Análisis de estadística descriptiva } \\
\text { de número de minas, agua } \\
\text { y superficie concesionados a la } \\
\text { minería por tipo de estatus de } \\
\text { disponibilidad de acuíferos }\end{array}$ \\
\hline $\begin{array}{l}\text { Situación de las cuencas } \\
\text { hidrológicas de Sonora hasta } \\
\text { diciembre de } 2015\end{array}$ & \begin{tabular}{|c|} 
Obtención de información \\
espacial del estatus de veda \\
de las cuencas hidrológicas \\
del estado en el portal \\
de datos del gobierno federal \\
(CONAGUA, 2015b)
\end{tabular} & $\begin{array}{l}\text { Análisis de estadística descriptiva } \\
\text { de número de minas, agua } \\
\text { y superficie concesionados a la } \\
\text { minería por tipo de estatus } \\
\text { de las cuencas hidrológicas }\end{array}$ \\
\hline
\end{tabular}

Fuente: elaboración propia. 
Efectos percibidos del cambio y la variabilidad climáticos y estrategias de adaptación del sector minero en Sonora

Esta fase se desarrolló entre mayo y agosto de 2019. Se obtuvo información de: a) las percepciones de distintos actores del sector minero respecto a los efectos del cambio y la variabilidad climáticos sobre las localidades donde se ubican sus empresas y sobre las compañías mineras mismas; b) los niveles de afectación, tanto actuales como futuros, de estos cambios sobre aspectos de la organización y producción minera; y 3) las estrategias que el sector minero emplea en la actualidad o que planea emplear en el futuro para enfrentar estos efectos. En términos del MDE, esto permitió definir los estresores y los shocks asociados con el cambio climático experimentados por las compañías mineras en el estado, así como las respuestas actuales o planeadas frente a dichos estresores y shocks.

Los datos se recabaron por medio un instrumento anónimo de 22 reactivos que incluye preguntas cerradas, de opción múltiple y de evaluación que utiliza escalas de 1 a 5 puntos. El cuestionario se distribuyó y se aplicó en línea mediante la plataforma SurveyMonkey ${ }^{\circledR}$ a una muestra no aleatoria de 25 representantes mineros contactados a través de las principales asociaciones profesionales del sector minero sonorense: Clúster Minero de Sonora, A. C. $(n=10)$; Asociación de Ingenieros de Minas, Metalurgistas y Geólogos de México, A. C. (AIMMGM), Capítulo Sonora $(n=15)$ y la Asociación Sonorense de Mineros, A. C. (AMS), de la que no se obtuvo respuesta. Luego se diseñó una base de datos y se hizo un análisis de estadística descriptiva de los reactivos empleando SPSS 25.0. Aunque presenta algunas limitaciones a la confiabilidad, para este estudio exploratorio se utilizó un instrumento en línea debido a las dificultades de acceso físico a los participantes (muchos de ellos están en locaciones remotas o no tienen tiempo ni espacio para responder en persona, de acuerdo con la experiencia de trabajo previa con este sector productivo).

Del total de participantes, 38\% trabajaban en compañías o plantas mineras; $42 \%$ en empresas y organizaciones prestadoras de servicios y/o productos al sector minero (consultoras, despachos de geología o tiendas de maquinaria o infraestructura); $12 \%$ en asociaciones o cámaras del sector minero y $8 \%$ no respondió la pregunta referente al tipo de organización donde trabaja. La mayoría de los informantes ocupa posiciones gerenciales o directivas en departamentos de medio ambiente y relaciones comunitarias. En términos de su distribución geográfica, $60 \%$ trabajaban en empresas u organizaciones del sector minero en Hermosillo; $16 \%$ en Sahuaripa y $4 \%$ en cada uno en los municipios de Altar, Arizpe, Caborca, La Colorada, y una organización fuera de Sonora (sumando 20\% en total). Sólo una persona (4\%) no respondió la pregunta sobre el lugar donde se ubica su organización.

Efectos combinados de minería y cambio climático

sobre la comunidad de Cucurpe

En la última fase se desarrollaron 13 entrevistas estructuradas a hombres y mujeres mayores de 18 años, habitantes de Cucurpe. Se aplicó la entrevista a través de un muestreo no aleatorio utilizando una técnica de bola de nieve en septiembre de 2018 con un seguimiento y nuevas entrevistas en octubre 
de 2019 (en total 10 mujeres y 3 hombres con edades de entre 27 y 60 años). Los temas abordados fueron: a) conocimientos y percepciones sobre el cambio climático y sus efectos, b) beneficios y costos relacionados con la actividad minera, c) nivel de afectación de diversos impactos climáticos sobre la comunidad y sobre la mina aledaña y d) estrategias de adaptación y sus posibles impactos locales. Esto permitió definir los estresores y los shocks combinados del cambio climático y la minería de gran escala experimentados por la comunidad, así como sus respuestas ante estresores y shocks presentes y futuros.

\section{Resultados}

Indicadores de seguridad hídrica y de minería en Sonora

En esta fase, el territorio estatal fue el marco de exposición; y las mineras, las unidades de exposición frente a estresores y shocks derivados del cambio climático. De acuerdo con el SGM, hasta 2017 existían 46 unidades mineras activas en Sonora, 22 extraían minerales metálicos y 24 no metálicos. Así mismo, de acuerdo con la Dirección de Minas de la Secretaría de Economía (SE), hasta 2015 la superficie concesionada para minería cubría alrededor de 3.8 millones de hectáreas (21\% del estado), amparadas por 4345 títulos (polígonos amarillos en la figura 3).

Figura 3. Unidades mineras activas en Sonora, 2017

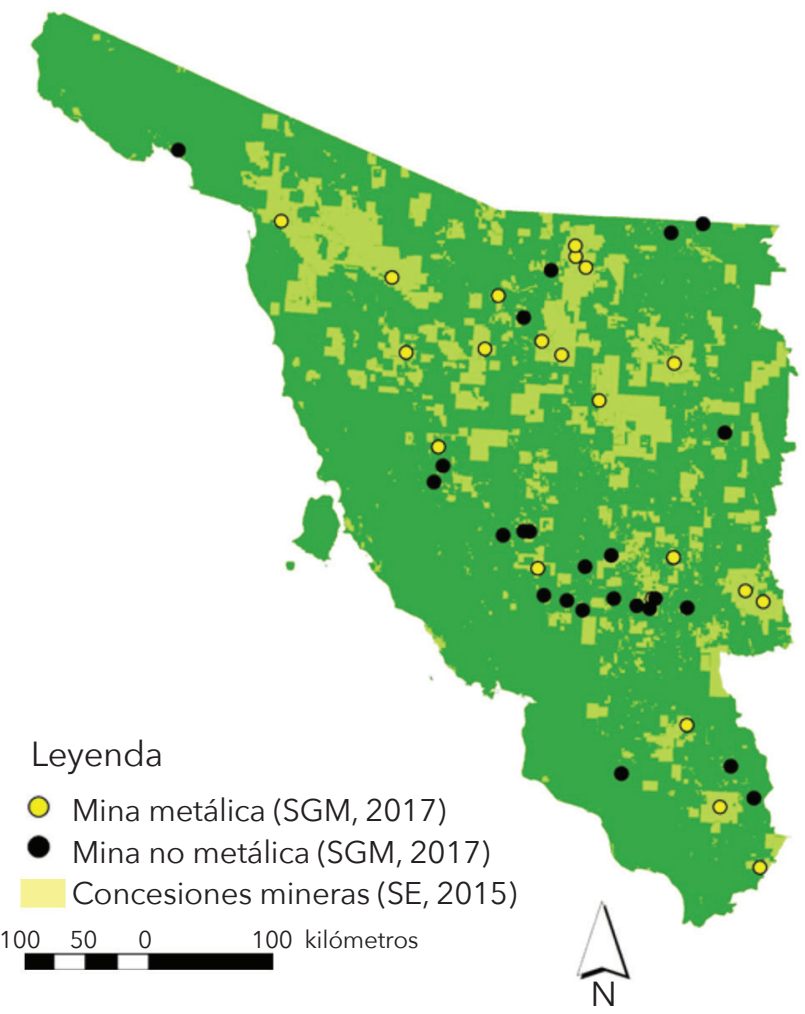

Fuente: elaboración propia. 
Para describir el contexto de las unidades de exposición (minas) y lo que podría afectar la emergencia de estresores y shocks hidro-climáticos, se triangularon varias fuentes de datos para identificar los títulos de concesión otorgados a mineras. Tomando como base el registro del SGM, se identificaron aquellas compañías que tenían título(s) de concesión registrados en REPDA en 2014, de acuerdo con el reporte de CartoCrítica y Heinrich Böll Stiftung (2016). Después se cotejaron estos registros con la base de datos del REPDA actualizada hasta agosto de 2019 (CONAGUA, 2019). Así se identificaron títulos para 22 minas activas de la lista del SGM (2017) que además contaban con registro en REPDA en 2019 y/o lo habían tenido en 2014 (véase figura 4).

Figura 4. Minas activas con registro identificado en REPDA hasta agosto de 2019

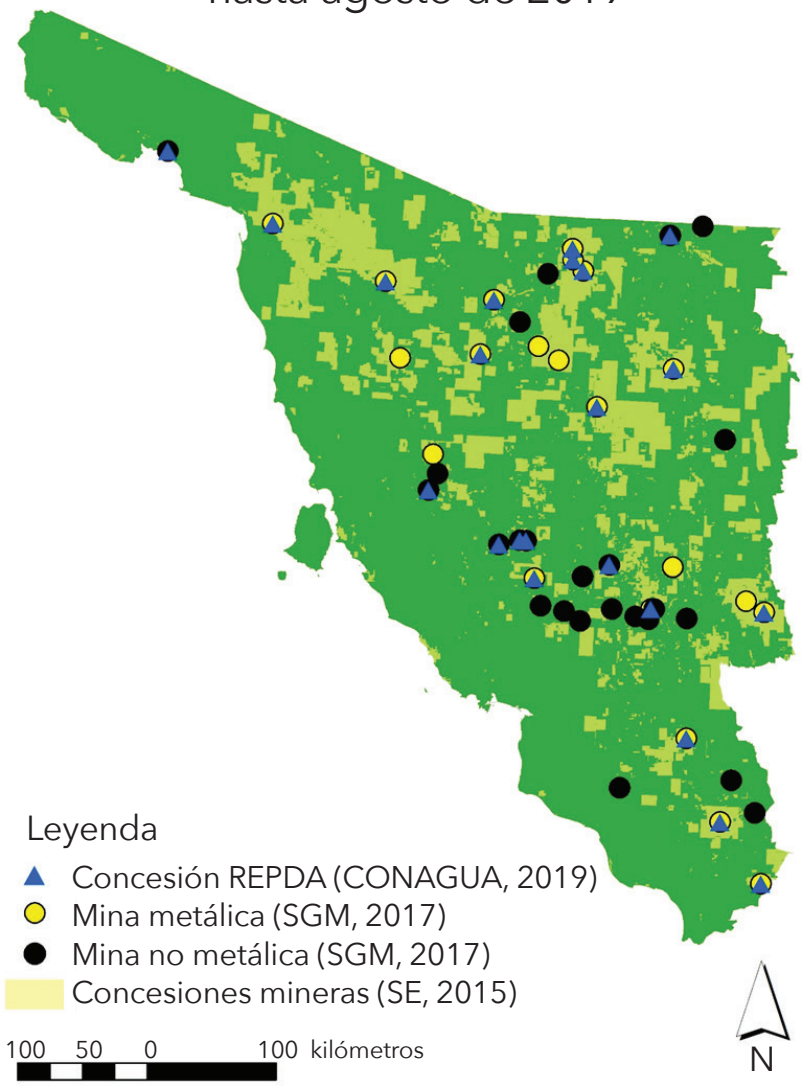

Fuente: elaboración propia.

Se enfrentaron varios retos para identificar estas concesiones, puesto que: 1) las minas pueden estar operando bajo diferentes nombres comerciales o utilizan nombres de representantes legales, lo que dificulta la homogeneidad en los registros del SGM, la SE y el REPDA; 2) no existe un uso específico denominado "minero" en la Ley de Aguas Nacionales, la mayoría de las minas tienen sus títulos bajo un uso industrial, de servicios o "diferentes usos"; 3 ) hay algunas instancias en las que las compañías no están obligadas a reportar el agua 
extraída (por ejemplo, no es obligatorio reportar el agua que se extrae como subproducto de una perforación minera en las minas subterráneas, aunque el agua se utilice en las instalaciones) y estos volúmenes no constituyen información pública; y 4) en relación con esto, muchos contratos de compraventa de aguas se realizan sin la correspondiente actualización en REPDA. Con el riesgo del subregistro, las concesiones en 2019 suman $123.3 \mathrm{Mm}^{3} /$ año, alrededor de $16 \mathrm{Mm}^{3} /$ año más que los reportados en el estudio de CartoCrítica y Heinrich Böll (2016) sobre Sonora (véase tabla 2). Esto representa una proporción relativamente pequeña del total concesionado para usos productivos en el estado, aunque equivale en términos gruesos al volumen anual para uso público urbano en Hermosillo, la capital del estado.

Para explorar las implicaciones hídricas de la actividad minera, se obtuvieron de la CONAGUA (2015a y 2015b) dos capas de información espacial que se presentan junto con las minas activas y la superficie concesionada a la minería. En la figura 5 y en la tabla 3 se muestran la distribución de minas activas, la superficie de tierra y los volúmenes de agua concesionados que corresponden a las áreas de acuíferos con y sin disponibilidad de agua (medida como la diferencia entre las extracciones y las entradas de agua subterránea).

Figura 5. Minas activas y estado de disponibilidad de los acuíferos, 2015

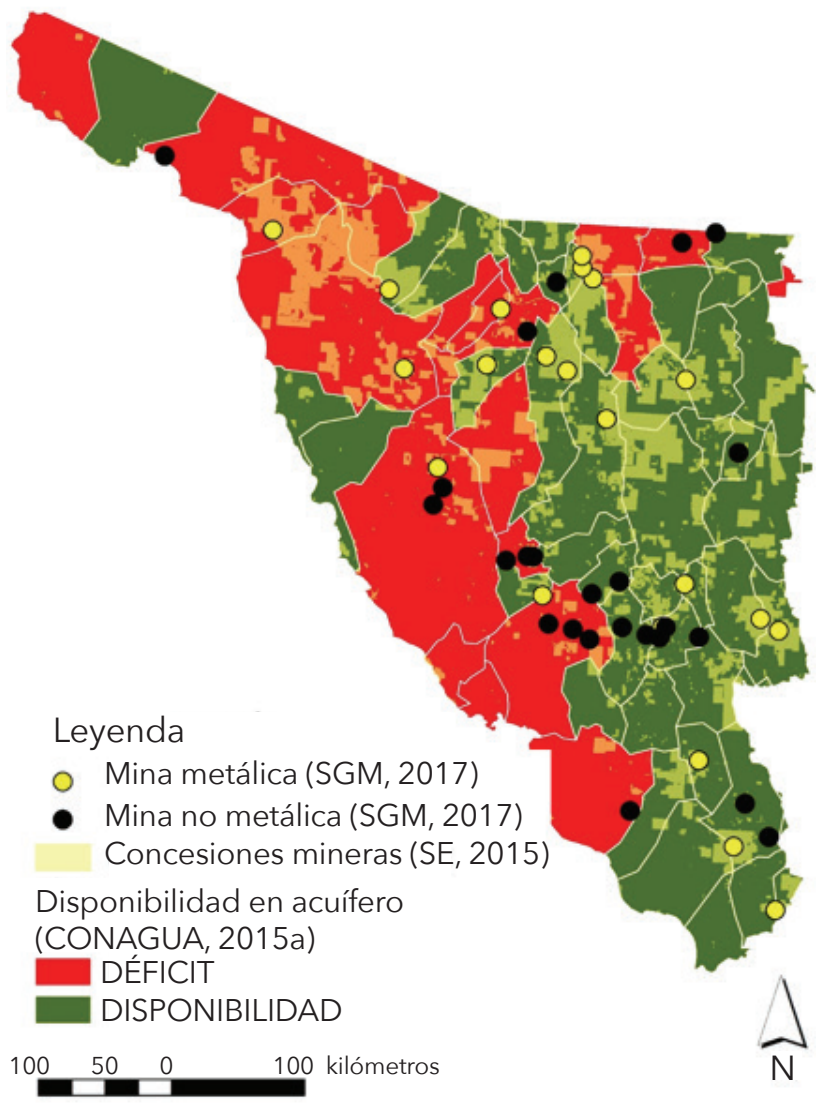

Fuente: elaboración propia. 


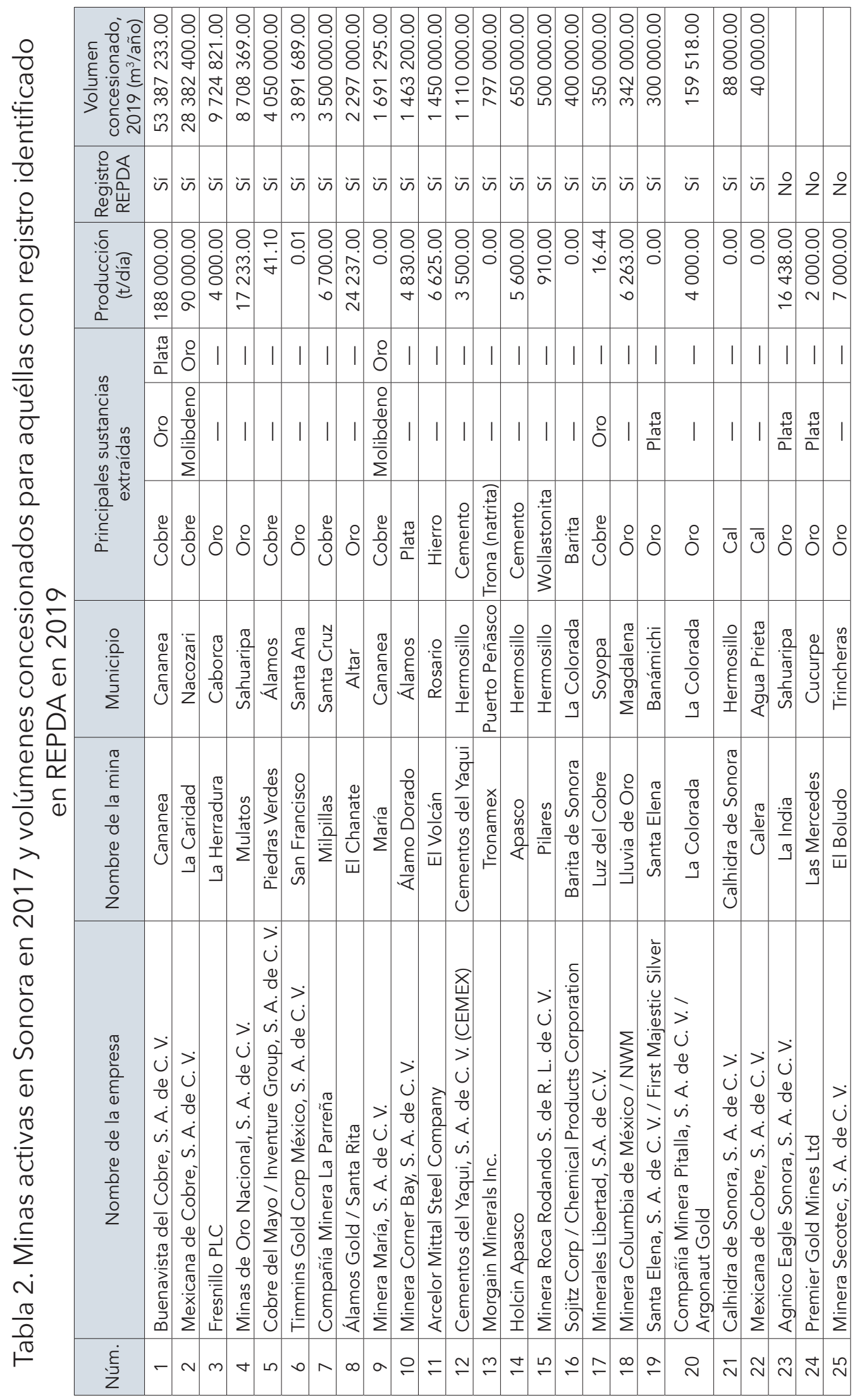




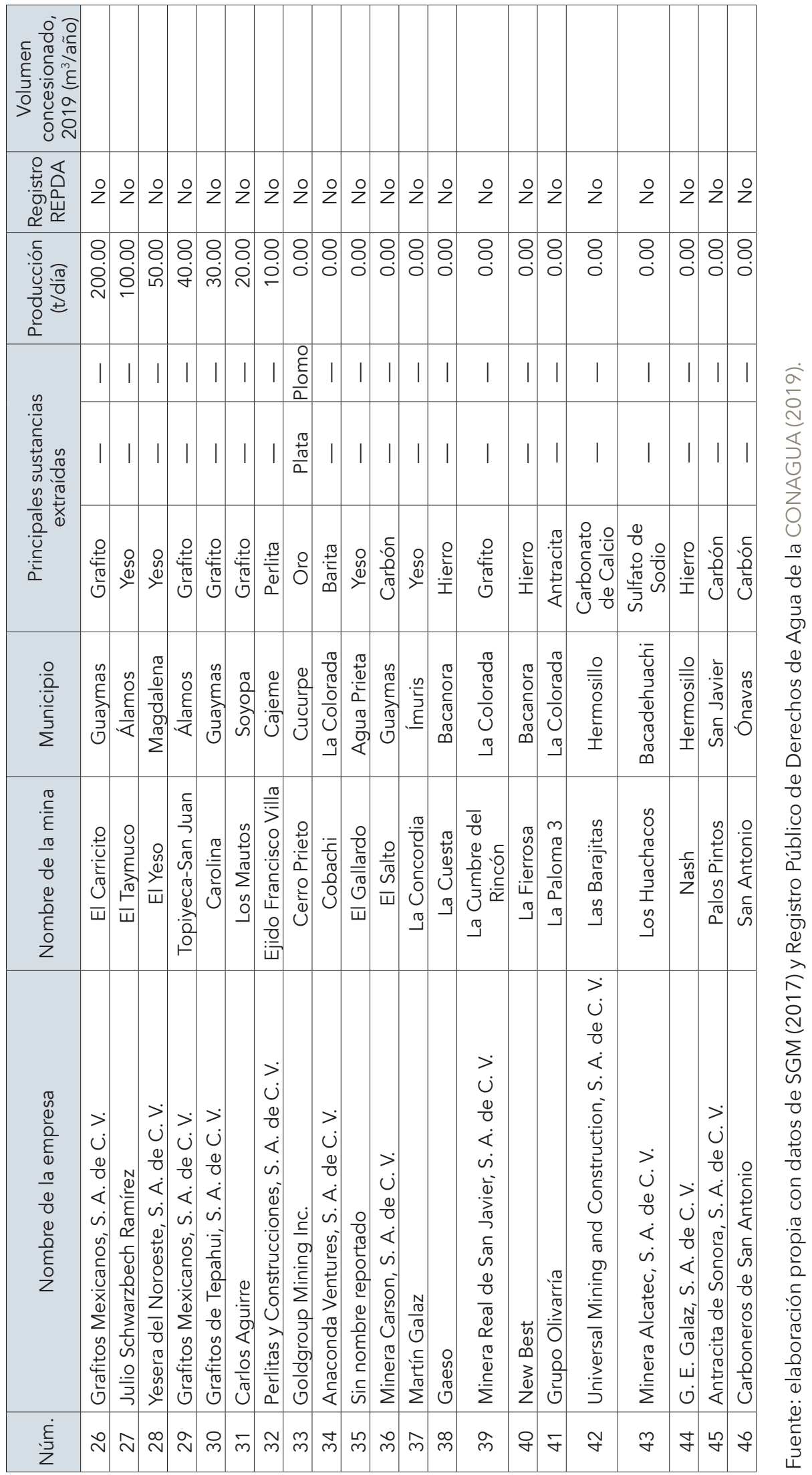


Tabla 3. Minas y concesiones mineras de agua y tierra por estatus de los acuíferos en Sonora

\begin{tabular}{|c|c|c|c|c|}
\hline $\begin{array}{c}\text { Estado del } \\
\text { acuífero }\end{array}$ & $\begin{array}{c}\text { Número de } \\
\text { minas } \\
\text { metálicas }\end{array}$ & $\begin{array}{c}\text { Número de } \\
\text { minas no } \\
\text { metálicas }\end{array}$ & $\begin{array}{c}\text { Concesiones } \\
\text { superficiales (ha) }\end{array}$ & $\begin{array}{c}\text { Volúmenes } \\
\text { REPDA (m³/año) }\end{array}$ \\
\hline Déficit & 5 & 12 & 1716788 & 66639054 \\
\hline Disponibilidad & 17 & 12 & 2498605 & 56643471 \\
\hline Total & 22 & 24 & 4215393 & 123282525 \\
\hline
\end{tabular}

Fuente: elaboración propia.

Aunque 29 de las 46 minas activas se encuentran en zonas correspondientes a los acuíferos con disponibilidad, en términos de volumen se extraen más de $66 \mathrm{Mm}^{3}$ /año de las zonas correspondientes a los acuíferos con déficit (áreas en color rojo), o 54\% del volumen total concesionado a minas activas en Sonora. Varias de las minas ubicadas en las zonas de los acuíferos con déficit extraen materiales metálicos, por lo general cobre, oro y plata, que requieren grandes cantidades de agua para lixiviación y que, a su vez, pueden impactar en la calidad del agua. Aunque un análisis del uso de agua por tipo de proceso escapa al alcance de este artículo, es recomendable realizar análisis técnicos detallados sobre el uso de agua por tipo de material y tecnología de extracción en Sonora.

Al considerar la existencia de vedas a la extracción en las cuencas hidrológicas, se observan 26 de las minas activas y más de la mitad del volumen de agua concesionado en cuencas con decreto de veda (véanse figura 6 y tabla 4). Las zonas de veda son

[...] aquellas áreas específicas de las regiones hidrológicas, cuencas hidrológicas o acuíferos, en las cuales no se autorizan aprovechamientos de agua adicionales a los establecidos legalmente y éstos se controlan mediante reglamentos específicos, en virtud del deterioro del agua en cantidad o calidad, por la afectación a la sustentabilidad hidrológica, o por el daño a cuerpos de agua superficiales o subterráneos. (CONAGUA, 2014)

Dadas estas condiciones, podría pensarse que algunos títulos posteriores a los decretos de veda serían inviables; sin embargo, el rango de las fechas de expedición de los permisos individuales va desde 1994 hasta 2018. El que existan títulos de concesión expedidos en fechas posteriores a los decretos de veda puede deberse a una renovación de los títulos expirados o a una adquisición por compra a otros usuarios. Sin embargo, no se cuenta con información para determinarlo. Globalmente, esta situación indica que la extracción de agua para la actividad minera en Sonora se encuentra en un contexto de serias limitaciones hídricas, tanto de agua subterránea como superficial. La concesión de tierra también se conecta con el comportamiento de las cuencas, puesto que las partes altas funcionan como zonas de captación de agua. 
Figura 6. Minas activas y estado de disponibilidad de las cuencas hidrológicas, 2015

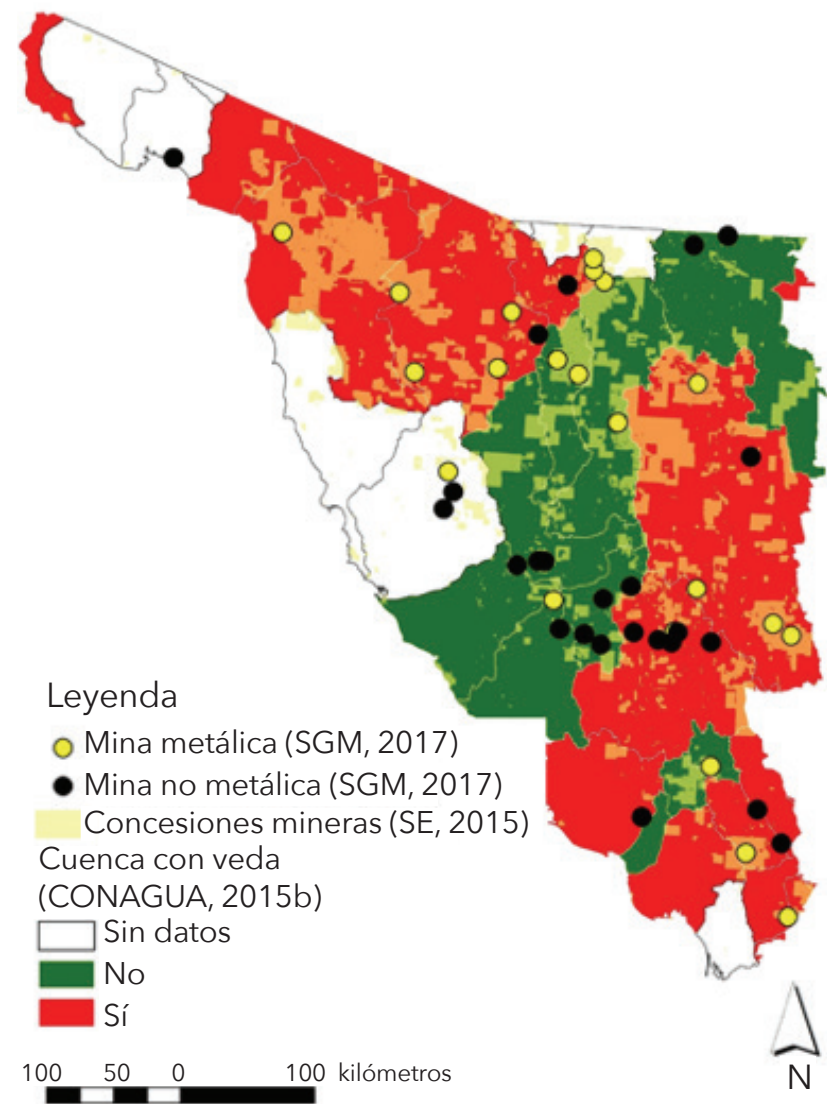

Fuente: elaboración propia.

Tabla 4. Minas y concesiones mineras de agua y tierra por estatus de cuencas en Sonora

\begin{tabular}{|c|c|c|c|c|}
\hline $\begin{array}{c}\text { Estado } \\
\text { de la cuenca }\end{array}$ & $\begin{array}{c}\text { Número } \\
\text { de minas } \\
\text { metálicas }\end{array}$ & $\begin{array}{c}\text { Número } \\
\text { de minas no } \\
\text { metálicas }\end{array}$ & $\begin{array}{c}\text { Concesiones } \\
\text { superficiales (ha) }\end{array}$ & $\begin{array}{c}\text { Volúmenes REPDA } \\
\text { (m3/año) }\end{array}$ \\
\hline Sí veda & 15 & 11 & 2719011.89 & 64400774 \\
\hline No veda & 6 & 10 & 1400765.44 & 57584751 \\
\hline Sin datos & 1 & 3 & 392436.24 & 1297000 \\
\hline Total & 22 & 24 & 4512213.57 & 123282525 \\
\hline
\end{tabular}

Fuente: elaboración propia. 
Efectos percibidos del cambio y la variabilidad climáticos y estrategias de adaptación del sector minero en Sonora

Se aplicó una encuesta utilizando la plataforma SurveyMonkey ${ }^{\circledR}$ para definir los estresores y los shocks del cambio climático percibidos por los representantes del sector minero y sus respuestas frente a ellos. Al preguntar "¿Has escuchado antes sobre el cambio climático o el calentamiento global?", la totalidad respondió que sí. A su vez, 18 de 25 (72\%) respondieron afirmativamente a la pregunta "¿Consideras que el cambio climático está ocurriendo en la localidad donde se encuentra tu organización o empresa?" En la pregunta "¿Qué efectos del cambio climático has observado en la localidad donde se encuentra tu organización o empresa?", 15 personas $(60 \%)$ indicaron mayores temperaturas. Otros impactos importantes fueron la variabilidad de las precipitaciones (14 o $56 \%$ ), las estaciones (14 o 56\%) y las temperaturas (13 o 52\%) (véase figura 7 ).

Figura 7. Efectos del cambio climático observados en la localidad donde se encuentran las organizaciones del sector minero

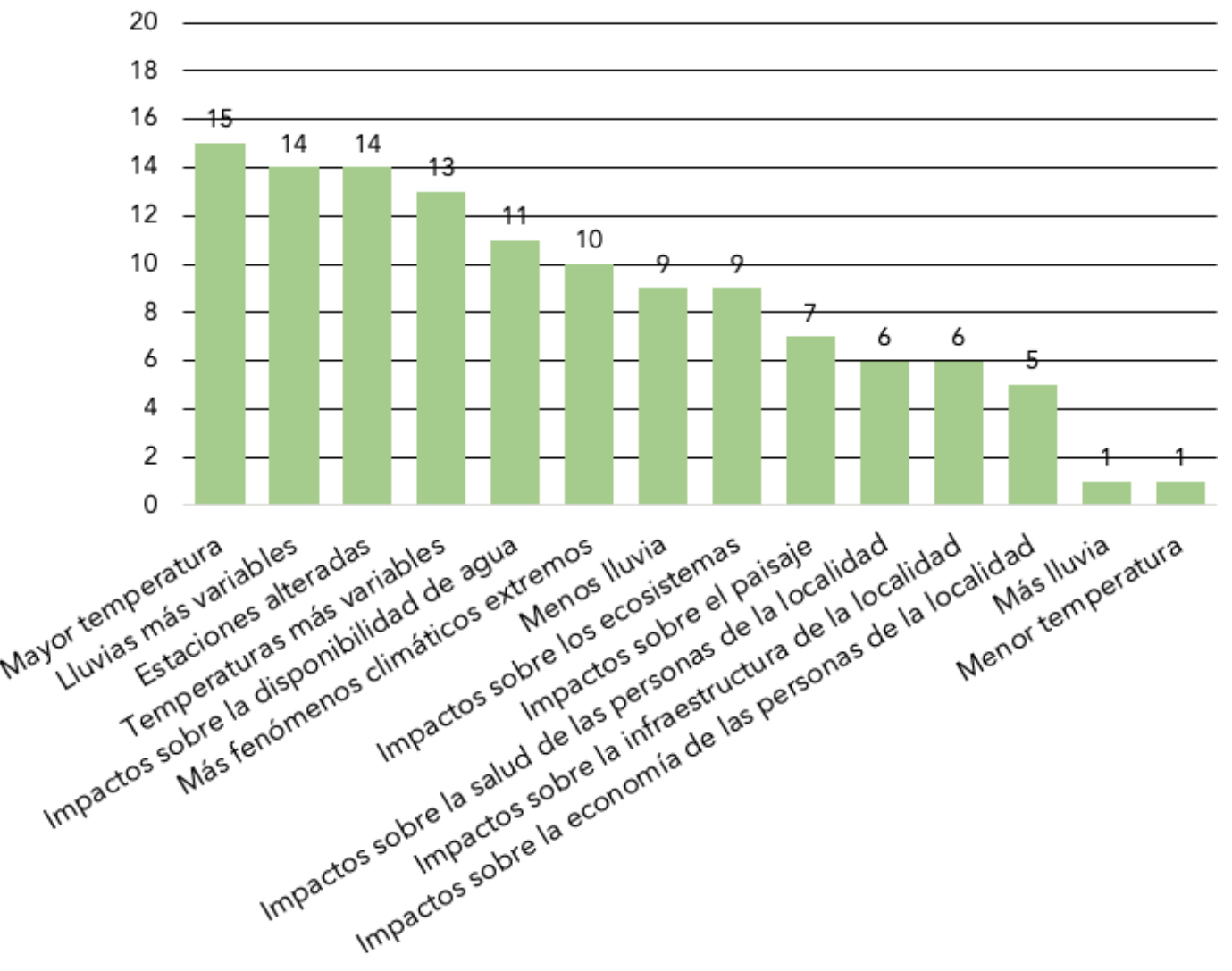

Fuente: elaboración propia. 
Al preguntar “¿Consideras que el cambio climático actualmente está afectando a la organización o empresa donde trabajas?”, 56\% (14 de 25) respondieron que sí. Además, se pidió evaluar el nivel de afectación actual de una lista de 14 tipos de estresores en una escala de cinco puntos ( $1=$ no afecta en nada, $2=$ afecta muy poco, $3=$ afecta en cierta medida, $4=$ afecta mucho, $5=$ afecta tanto que la organización podría cerrar o cesar operaciones). Los estresores relacionados con impactos sobre la disponibilidad de agua obtuvieron el mayor puntaje promedio (3.87), seguido por impactos sobre la salud de las personas (3.65) y fenómenos extremos (3.52) (véase figura 8).

Figura 8. Nivel de afectación actual de cada tipo de estresor o shock sobre las organizaciones del sector minero

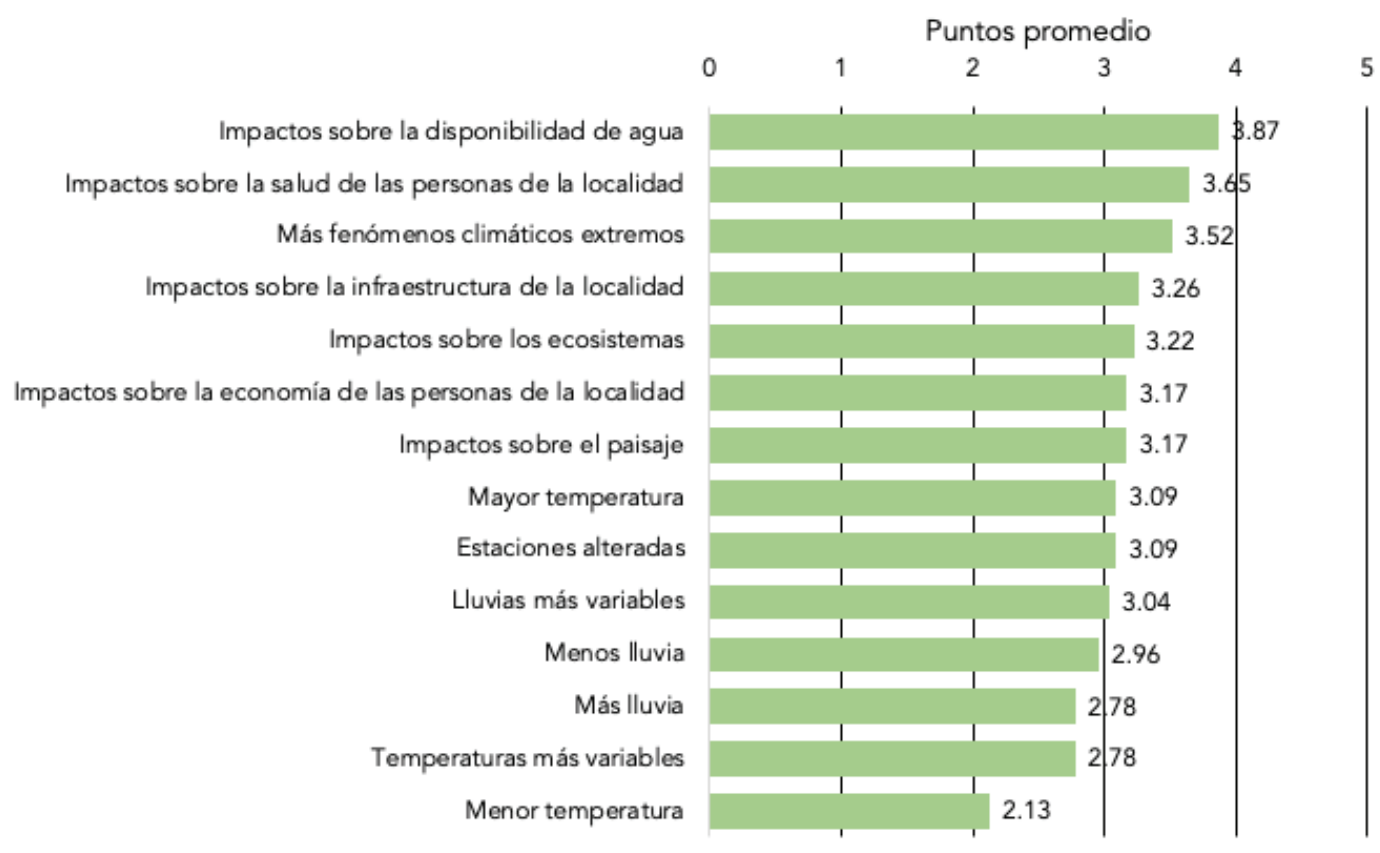

Fuente: elaboración propia.

Mientras que poco más de la mitad consideró que en la actualidad el cambio climático afecta a sus organizaciones, 19 de 25 (más de tres cuartas partes) respondieron que sí a la pregunta "Si el cambio climático actualmente no afecta a tu organización o empresa, ¿consideras que podría afectarla en el futuro?" También se les pidió evaluar el nivel de afectación que cada estresor podría tener en el futuro sobre sus organizaciones utilizando una escala de cinco puntos similar a la pregunta anterior. Los estresores relacionados con impactos sobre la disponibilidad de agua presentaron de nuevo el puntaje promedio más alto (3.91), seguidos por fenómenos climáticos extremos (3.82) e impactos sobre la salud de las personas de la localidad (3.55) (véase figura 9). 
Figura 9. Nivel de afectación futuro de cada tipo de estresor o shock sobre las organizaciones del sector minero

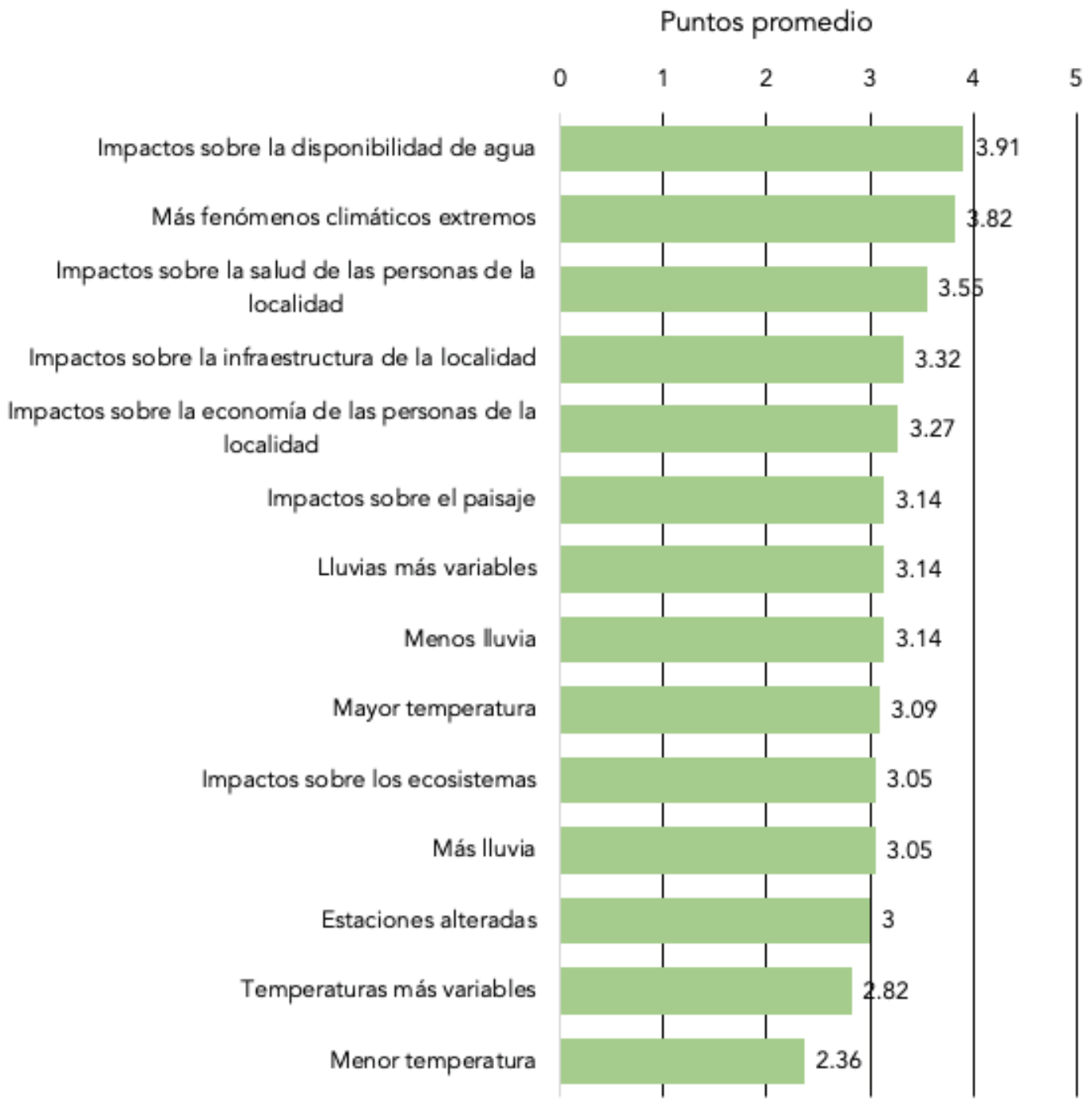

Fuente: elaboración propia.

Considerando el nivel de impacto actual y futuro percibido por los representantes del sector minero para estos estresores y shocks, 18 de 25 (72\%) señalaron que su organización está desarrollando en la actualidad respuestas para enfrentar el cambio climático. Al pedirles "De la siguiente lista, escoge todos aquellos tipos de estrategias que tu organización o empresa esté realizando actualmente para hacer frente al cambio climático", las respuestas seleccionadas con mayor frecuencia fueron los programas o políticas corporativas para el reciclaje de materiales o ahorro de recursos (15), el uso adecuado del agua (14) y el uso adecuado de la energía (13) (véase tabla 5). Los programas de 
Tabla 5. Respuestas al cambio climático empleadas actualmente y planeadas en el futuro por las organizaciones o empresas del sector minero

\begin{tabular}{|c|c|c|c|}
\hline Núm. & Respuestas & $\begin{array}{l}\text { Actuales } \\
\%\end{array}$ & $\begin{array}{l}\text { Futuras } \\
\%\end{array}$ \\
\hline 1 & $\begin{array}{l}\text { Establecimiento de sistemas de gestión para adaptarse } \\
\text { al cambio climático }\end{array}$ & $\begin{array}{c}3 \\
12 \% \\
\end{array}$ & $\begin{array}{c}6 \\
24 \% \\
\end{array}$ \\
\hline 2 & Producción de información climática local & $\begin{array}{c}7 \\
28 \% \\
\end{array}$ & $\begin{array}{c}4 \\
16 \%\end{array}$ \\
\hline 3 & $\begin{array}{c}\text { Modelamiento climático para cuantificar y proyectar riesgos } \\
\text { y oportunidades locales }\end{array}$ & $\begin{array}{c}4 \\
16 \%\end{array}$ & $\begin{array}{c}4 \\
16 \% \\
\end{array}$ \\
\hline 4 & $\begin{array}{c}\text { Implementación de estrategias para identificar y disminuir riesgos } \\
\text { climáticos }\end{array}$ & $\begin{array}{c}10 \\
40 \%\end{array}$ & $\begin{array}{c}7 \\
28 \% \\
\end{array}$ \\
\hline 5 & $\begin{array}{c}\text { Toma de decisiones que incluyan consideraciones climáticas } \\
\text { a mediano y largo plazo }\end{array}$ & $\begin{array}{c}9 \\
36 \%\end{array}$ & $\begin{array}{c}7 \\
28 \% \\
\end{array}$ \\
\hline 6 & $\begin{array}{c}\text { Mejoramiento y reforzamiento de la infraestructura y las } \\
\text { instalaciones para hacerlas resistentes a riesgos climáticos } \\
\text { e hidrológicos }\end{array}$ & $\begin{array}{c}8 \\
32 \%\end{array}$ & $\begin{array}{l}8 \\
32 \%\end{array}$ \\
\hline 7 & $\begin{array}{c}\text { Revisión de procedimientos para responder a emergencias } \\
\text { y desarrollo de planes de contingencia }\end{array}$ & $\begin{array}{c}11 \\
44 \% \\
\end{array}$ & $\begin{array}{c}10 \\
40 \%\end{array}$ \\
\hline 8 & $\begin{array}{c}\text { Implementación de mejores estrategias y tecnologías para el uso } \\
\text { y la gestión del agua }\end{array}$ & $\begin{array}{c}10 \\
40 \%\end{array}$ & $\begin{array}{c}10 \\
40 \% \\
\end{array}$ \\
\hline 9 & $\begin{array}{l}\text { Implementación de mejores estrategias y tecnologías para el uso } \\
\text { y la gestión de la energía }\end{array}$ & $\begin{array}{c}13 \\
52 \% \\
\end{array}$ & $\begin{array}{c}9 \\
36 \% \\
\end{array}$ \\
\hline 10 & $\begin{array}{c}\text { Implementación de mejores estrategias y tecnologías } \\
\text { para reducir emisiones GEl }\end{array}$ & $\begin{array}{c}9 \\
36 \% \\
\end{array}$ & $\begin{array}{c}10 \\
40 \% \\
\end{array}$ \\
\hline 11 & Expansión y diversificación del portafolio de productos & $\begin{array}{c}4 \\
16 \% \\
\end{array}$ & $\begin{array}{c}2 \\
8 \% \\
\end{array}$ \\
\hline 12 & $\begin{array}{l}\text { Búsqueda de innovaciones técnicas y colaboración con otros } \\
\text { sectores para encontrar soluciones frente a climas extremos }\end{array}$ & $\begin{array}{c}7 \\
28 \% \\
\end{array}$ & $\begin{array}{c}4 \\
16 \% \\
\end{array}$ \\
\hline 13 & $\begin{array}{l}\text { Programas corporativos de reciclaje de materiales y ahorro de } \\
\text { recursos }\end{array}$ & $\begin{array}{c}15 \\
60 \%\end{array}$ & $\begin{array}{c}12 \\
48 \%\end{array}$ \\
\hline 14 & $\begin{array}{c}\text { Programas corporativos para educar a los empleados } \\
\text { sobre el cambio climático }\end{array}$ & $\begin{array}{c}8 \\
32 \% \\
\end{array}$ & $\begin{array}{c}14 \\
56 \%\end{array}$ \\
\hline 15 & Programas corporativos para el uso adecuado del agua & $\begin{array}{c}14 \\
56 \%\end{array}$ & $\begin{array}{c}16 \\
64 \% \\
\end{array}$ \\
\hline 16 & Programas corporativos para el uso adecuado de la energía & $\begin{array}{c}13 \\
52 \%\end{array}$ & $\begin{array}{c}15 \\
60 \%\end{array}$ \\
\hline 17 & $\begin{array}{c}\text { Programas comunitarios de reciclaje de materiales y ahorro } \\
\text { de recursos en la localidad }\end{array}$ & $\begin{array}{c}11 \\
44 \% \\
\end{array}$ & $\begin{array}{c}11 \\
44 \% \\
\end{array}$ \\
\hline 18 & $\begin{array}{l}\text { Programas comunitarios para educar a los habitantes sobre } \\
\text { el cambio climático }\end{array}$ & $\begin{array}{c}7 \\
28 \% \\
\end{array}$ & $\begin{array}{c}11 \\
44 \% \\
\end{array}$ \\
\hline 19 & Programas comunitarios para el uso adecuado del agua & $\begin{array}{c}9 \\
36 \% \\
\end{array}$ & $\begin{array}{c}9 \\
36 \% \\
\end{array}$ \\
\hline 20 & Programas comunitarios para el uso adecuado de la energía & $\begin{array}{c}5 \\
20 \% \\
\end{array}$ & $\begin{array}{c}9 \\
36 \% \\
\end{array}$ \\
\hline 21 & $\begin{array}{c}\text { Inversión directa en infraestructura para manejo de agua } \\
\text { en localidad }\end{array}$ & $\begin{array}{c}2 \\
4 \% \\
\end{array}$ & $\begin{array}{c}2 \\
8 \% \\
\end{array}$ \\
\hline 22 & $\begin{array}{l}\text { Inversión directa en infraestructura para servicio de energía } \\
\text { en la localidad }\end{array}$ & $\begin{array}{c}6 \\
24 \% \\
\end{array}$ & $\begin{array}{c}7 \\
28 \% \\
\end{array}$ \\
\hline 23 & Ninguna de las anteriores & $\begin{array}{c}1 \\
4 \%\end{array}$ & $\begin{array}{c}1 \\
4 \%\end{array}$ \\
\hline 24 & No sé & $\begin{array}{c}1 \\
4 \%\end{array}$ & $\begin{array}{c}1 \\
4 \%\end{array}$ \\
\hline
\end{tabular}

Fuente: elaboración propia. 
adaptación conjunta de la mina con las comunidades fueron infrecuentes, así como las respuestas relacionadas de manera directa con el clima (por ejemplo, monitoreo de variables climáticas). Aunque se reconocen los impactos sobre el agua, las respuestas sugieren una gestión centrada en el funcionamiento interno con objetivos de eficiencia productiva, más que una visión de las minas como parte de un sistema hidrológico y social interconectado que necesita adaptarse a impactos climáticos e hidrológicos.

Mientras que dos terceras partes respondieron que en el futuro consideran que el cambio climático afectará a sus empresas y organizaciones, sólo 14 de 25 (56\%) respondieron que su organización planea hacer algo frente a los efectos del cambio climático en el futuro. Las respuestas más frecuentes son los programas corporativos para el uso adecuado del agua (16) y la energía (15), y para educar a los empleados sobre el cambio climático (14) (véase tabla 5). La educación sobre el cambio climático aparece como respuesta futura, aunque enfocada sólo en los empleados. Una vez más, los programas o las acciones que conectan las minas con las comunidades, así como otras respuestas relacionadas con el cambio climático, fueron infrecuentes.

Efectos combinados de minería y de cambio climático sobre Cucurpe

En esta fase, la unidad de exposición cambia de las minas a los hogares de la cabecera municipal de Cucurpe, con el mismo nombre. Ésta se encuentra a unos veinte kilómetros hacia el oeste de Las Mercedes. Es una mina subterránea de oro y plata propiedad de la empresa norteamericana Premier Gold Limited (Ltd). Cucurpe se encuentra a $235 \mathrm{~km}$ al noreste de Hermosillo y a menos de 140 $\mathrm{km}$ al sur de la frontera con Estados Unidos. Las actividades económicas más extendidas son la ganadería y la agricultura con algunas contribuciones de la minería y el sector terciario (pequeños comercios en Cucurpe y en el municipio vecino de Magdalena, donde algunos habitantes trabajan y hacen compras). En 2015, en 308 hogares, en el municipio vivían 965 personas, 55.3\% hombres y 44.7\% mujeres (Instituto Nacional de Estadística y Geografía, 2015).

Las Mercedes abrió sus operaciones hace cerca de diez años. Su producción en 2017 rondaba los $2342 \mathrm{~kg}$ de oro y los $9582 \mathrm{~kg}$ de plata (4.9 y 2.2\% de la producción estatal de esos minerales en ese año, respectivamente) (Premier Gold Ltd, 2018; SGM, 2017). En 2017 tenía 715 empleados, 60\% (428) dependían de manera directa de la razón social de la empresa y 40\% (287) eran subcontratados (Premier Gold Ltd., 2018). Cerca de cien empleados y empleadas eran de Cucurpe, según la autoridad municipal entrevistada.

Al analizar las respuestas de los habitantes de Cucurpe, emergieron tres grandes asuntos, contradictorios en apariencia, que podrían informar las relaciones futuras entre las minas y las comunidades en un contexto de cambio climático. La primera de estas contradicciones se refiere a la contraposición entre el cambio climático como "nuevo" estresor versus la variabilidad histórica natural de la región. La segunda se refiere a los beneficios económicos y materiales que la mina ha traído a la comunidad versus los efectos desconocidos y potencialmente perjudiciales a los otros medios de vida locales, dependientes 
de recursos hídricos escasos y vulnerables. La tercera contradicción surge entre la incertidumbre en el mantenimiento de la calidad y la cantidad del agua versus el mantenimiento de la seguridad en otros servicios locales.

a) Cambio climático como "nuevo" estresor versus la variabilidad natural de la región Al abordar el conocimiento y las percepciones sobre el cambio climático, la mayoría de los informantes señalaron haber escuchado el término. Aunque no sabían con certeza sus causas, sí pudieron identificar cambios en el clima que se configuraban como estresores locales (mayores temperaturas y precipitación más variable), lo cual es congruente tanto con los reportes de los participantes mineros como con los estudios climáticos regionales reportados previamente en este artículo. De cualquier manera, algunos informantes también señalaron que el clima siempre ha sido extremoso en la región y ha sido necesario adaptarse a cambios mayores o menores.

La percepción del cambio climático es una precondición necesaria, mas no suficiente para responder a él (Grothmann y Patt, 2005). Al preguntar si consideran que el cambio climático afectará a la minería local y si ésta tendrá capacidad para adaptarse, los entrevistados coincidieron en que, a excepción de que hubiera lluvias muy fuertes (por ser una instalación bajo tierra), la mina no sería afectada en mayor grado y, en caso de que lo fuera, cuenta con recursos suficientes para responder a esos estresores. Existen incongruencias entre la importancia de los estresores y shocks climáticos percibidos por los representantes del sector minero y aquellos que los habitantes de Cucurpe perciben como importantes para la actividad minera local.

Al preguntar si consideraban que las acciones de adaptación de las minas podrían afectar a Cucurpe en materia de agua, los entrevistados (entre quienes se encontraban una autoridad municipal y una comunera y líder local) señalaron que nunca habían tenido problemas con la mina por falta de agua en los pozos agrícolas o ganaderos ni en la comunidad. Aunque en el REPDA no se encontraron volúmenes concesionados a la mina Las Mercedes (véase el registro núm. 24 en la tabla 2), ésta reporta que utiliza entre 9000 y $15000 \mathrm{~m}^{3} /$ mes provenientes de reutilización de agua de jales, de acceso a pozos a través de la compra de derechos y de bombear el agua de su perforación subterránea (Premier Gold Ltd., 2018). Así mismo, de acuerdo con la entrevista a una empleada de la mina y habitante de Cucurpe, también se compra agua potable en pipas para usos del campamento humano, porque es más económico que tratar agua de las otras fuentes. Desafortunadamente, no fue posible obtener respuestas de los representantes de Las Mercedes a la encuesta para confirmar esta información. Sin embargo, las respuestas a la encuesta por parte del sector minero como a la entrevista por parte de los habitantes de la comunidad, indican de manera global una desconexión entre las estrategias corporativas y comunitarias frente a los estresores comunes del cambio climático, lo que probablemente se deba a la percepción de que la mina no ha tenido efectos sobre el agua de la comunidad (y de este modo, está desconectada), así como una tendencia a ver como sistema cerrado el propio sector minero, que no reconoce la pertenencia de las minas a sistemas socio-ecológicos más amplios. 
b) Beneficios materiales evidentes versus efectos perjudiciales no visibles Uno de los aspectos más importantes en el que coincidieron casi todos los habitantes fueron los beneficios económicos y materiales obtenidos de la mina. Los dueños anteriores (la canadiense Yamana Gold Inc.) al inicio de sus operaciones, establecieron un programa a través del cual los pobladores podían obtener fondos semilla para pequeños negocios. De esta manera, se abrió la primera farmacia y una purificadora de agua. También varias amas de casa abrieron hostales y comedores en sus hogares para los empleados de la mina. Sin embargo, cuando ésta cambió de dueños y se abrió el campamento humano en la mina, bajó la demanda para esos servicios prestados por los hogares locales. Con todo, la comunera entrevistada señaló que "ojalá la mina no se vaya". Es posible saber quiénes trabajan en las minas porque "hasta andan mejor vestidas". La mina continúa en la actualidad con un programa de becas para los hijos de los comuneros de Cucurpe, da apoyo a actividades deportivas y culturales y dona horas de trabajo-máquina para los agricultores de la comunidad.

Otro aspecto importante en cuanto a desarrollo material que puede mejorar la capacidad de respuesta de la comunidad ante el cambio climático, es la inversión del Fondo para el Desarrollo Regional Sustentable de Estado y Municipios Mineros, o Fondo Minero, establecido por el gobierno federal en 2014 y al cual las compañías mineras contribuyen para fomentar el desarrollo de las localidades mineras. En el periodo de 2014 a 2017, Cucurpe recibió alrededor de 78 millones de pesos, que se utilizaron para la pavimentación de las calles y el mejoramiento de los edificios públicos. Sin embargo, este programa se dirigía específicamente a la construcción de infraestructura física. Hay ausencia de inversión para los programas de construcción de capacidades para que la comunidad pueda desarrollarse una vez que cierre la mina. Tampoco se observa inversión para mejorar la respuesta de la comunidad frente a impactos potenciales del cambio climático y de la minería misma.

Por otra parte, los entrevistados no reportan afectaciones visibles de la mina sobre sus medios de vida o sus recursos naturales. Ésta se encuentra aproximadamente a $20 \mathrm{~km}$ al oriente de la localidad y es subterránea, por lo que sus impactos pueden no ser tan visibles como en sistemas a cielo abierto. El único evento perjudicial reportado por dos entrevistadas fue que la mina, al inicio de sus operaciones, utilizaba la laguna de aguas residuales de la localidad para verter el agua residual del campamento humano, lo que generaba una sobrecarga en las instalaciones, ya de por sí limitadas, y esto ocasionaba malos olores en el vecindario cercano a la laguna. De acuerdo con las informantes, los afectados pidieron al ayuntamiento que la mina gestionara sus residuos en su propio sitio, con lo cual el problema se detuvo. En ese tiempo, una de las vecinas era suplente de un funcionario municipal de Cucurpe, lo cual podría haber favorecido en los resultados favorables a esta petición.

Es posible que los beneficios materiales de corto y mediano plazo en Cucurpe se contrapongan a los estresores y shocks hidrológicos que no son observados ni previstos. Aunque los procesos de la minería globalizada y el cambio ambiental global están operando de manera combinada, en este punto no han generado estresores particulares sobre el marco de exposición de la localidad 
o sus hogares, de acuerdo con los entrevistados. Para muchos de ellos, las ganancias económicas y materiales de la actividad minera tienen resultados más sobresalientes que las afectaciones potenciales, o los impactos hídricos son más difíciles de observar en las escalas temporales y espaciales correspondientes al nivel comunitario. Esto no significa que algunos habitantes no hayan referido incertidumbre con respecto a la mina y al agua, como se indica más adelante.

c) Incertidumbre en la seguridad hídrica versus

calidad y seguridad de otros servicios

En términos de seguridad hídrica, en este trabajo se ha considerado sólo la dimensión de cantidad de agua, y hasta el momento del estudio los entrevistados señalaron la ausencia de afectaciones sobre los pozos que se utilizan para surtir a los hogares y a las actividades agropecuarias. Sin embargo, algunos informantes también indicaron incertidumbre sobre el futuro del agua, no necesariamente asociada al cambio climático, sino a los impactos de la contaminación antropogénica, tanto de la mina como de la laguna de aguas residuales de la misma localidad.

En 2014, el río Sonora sufrió los efectos de un derrame de lixiviado de la presa de jales de Buenavista del Cobre, una de las minas de cobre más grandes de América Latina, ubicada en Cananea (Díaz-Caravantes, Duarte Tagles y Durazo, 2016). Este evento sentó precedente para las comunidades rurales mineras en Sonora. La autoridad municipal de Cucurpe señaló que el ayuntamiento ha preguntado a la CONAGUA si se vigila el funcionamiento de la presa de jales. Sin embargo, no está segura de que realmente se supervise y ha solicitado documentos donde se avale que todo está en orden. Según el informante, le preocupa que ocurra lo mismo que en Cananea; pero al preguntársele si considera que la comunidad está en riesgo debido a un derrame, contestó que esto nunca ha pasado y que la mina está construyendo una nueva presa, lo que pudo confirmarse en el reporte técnico de Premier Gold Ltd. (2018).

Algunos entrevistados señalaron que el principal riesgo de contaminación no provendría de la presa de jales de Las Mercedes (o de cualquiera de las otras dos minas que se encuentran en prospección en Cucurpe hasta el momento de publicación de este artículo), sino que hay un riesgo potencial en la laguna de aguas residuales, pues se encuentra casi al límite de su capacidad y muy cerca de uno de los dos afluentes principales del río San Miguel, aguas arriba del pueblo. Ésta es una situación que han reportado habitantes de varias comunidades del estado; sin embargo, no existen estudios sistemáticos de la calidad del agua en muchos de estos sitios. Aunque los estresores originados por las dinámicas comunitarias (en este caso, infraestructura municipal deficiente) no habían sido originalmente considerados en esta investigación, al recolectar datos, éstos emergieron como un grupo más de factores que pueden interactuar con el cambio climático y con la minería a gran escala y producir estresores más complejos para la comunidad. En ello intervienen muchos factores, tales como la falta de inversión pública en localidades rurales, el envejecimiento de los sistemas de agua potable y alcantarillado, la debilidad institucional y los incre- 
mentos demográficos debido a la atracción de personas que llegan a Cucurpe para trabajar en la minería.

Por otra parte, aunque ninguno de los habitantes relacionó de forma explícita los riesgos de un derrame con las lluvias variables, las proyecciones indican que la variabilidad podría manifestarse como fenómenos de precipitación de corta duración, aunque muy intensos, lo cual sobrecargaría la capacidad de la infraestructura local, tanto municipal como minera, para detener los flujos de agua, haciendo más probable la contaminación antropogénica y minera. Con todo, los habitantes perciben este riesgo como bajo y se ve compensado por el acceso a oportunidades materiales, sobre todo para aquéllos sin actividades agrarias. De este modo, los hogares sin tierras ni animales procuran medios de vida alternativos aun cuando representen riesgos ambientales y colectivos mayores.

\section{Discusión y conclusiones}

Este trabajo exploró cómo el cambio climático impacta en el sector minero sonorense, cómo responde ante dichos estresores y shocks y cómo esto, a su vez, puede generar efectos en cascada que colocan a las comunidades rurales mineras en una situación de doble exposición con impactos potenciales a su seguridad hídrica. Esto se realizó mediante el análisis espacial de indicadores hídricos en relación con la minería; el análisis estadístico de una encuesta a representantes del sector minero para identificar estresores y shocks climáticos sobre la minería y las respuestas actuales y futuras de las organizaciones del sector; y, por último, entrevistas a los habitantes de Cucurpe para ejemplificar estresores combinados derivados de la minería y el cambio climático a nivel local, así como las respuestas ante ellos. Aunque se han evaluado de manera indirecta las relaciones entre minería y seguridad hídrica en su dimensión cuantitativa, hay indicadores para sostener que ante un escenario de mayores temperaturas y variabilidad hidrológica, la seguridad hídrica tanto de la minería como de las comunidades rurales mineras podría verse muy afectada en sus dimensiones cuantitativa y cualitativa.

El agua concesionada a las 22 minas que se identificaron en el REPDA equivale a cerca de $123.3 \mathrm{Mm}^{3} /$ año. Aunque esto es una proporción menor del agua empleada en actividades productivas en general, y en la industria sonorense en particular, es en términos gruesos el volumen que la ciudad de Hermosillo requiere al año para sus más de 800 mil habitantes. Del mismo modo, una gran cantidad de concesiones de tierra y agua para la minería se encuentra en zonas correspondientes a los acuíferos sin disponibilidad y a las cuencas que tienen algún tipo de restricción a la extracción. Siguiendo los conceptos del MDE, el contexto en el que funcionan muchas minas y comunidades rurales del estado se encuentra con importantes barreras hídricas. La acumulación progresiva de recursos en pocas manos corporativas podría potenciar en este contexto conflictos entre los usuarios del agua en un futuro en el que se proyectan disminuciones de precipitación y aumento de las temperaturas. 
Al mismo tiempo, existen importantes limitaciones a las conclusiones que pueden obtenerse a través del análisis de datos del REPDA, debido a la poca sistematicidad y calidad en los registros, y también por la debilidad de los marcos legales para organizar y dar seguimiento al uso del agua por parte de distintos sectores. En este sentido, existe una importante oportunidad de colaboración entre la CONAGUA y el sector minero a través de la sistematización de prácticas de información y trasparencia, así como el establecimiento de estándares que respondan de manera adecuada a los escenarios de cambio climático proyectados para Sonora y que indican como un reto mayúsculo el logro de la seguridad hídrica humana y el sostenimiento de la capacidad productiva en nuevas condiciones ambientales.

En cuanto a las percepciones de los estresores derivados del cambio climático, existen coincidencias entre los representantes del sector minero y los habitantes de Cucurpe respecto a la ocurrencia de mayores temperaturas, así como una alta variabilidad de las lluvias e impactos hidrológicos. Para el sector minero, los estresores climáticos con mayor peso en la actualidad y en el futuro se refieren a las afectaciones en la disponibilidad de agua. Un aspecto también común a ambos grupos es lo que aparece como una desarticulación entre las respuestas de la mina frente a condiciones climáticas cambiantes y las respuestas de los propios habitantes de Cucurpe. Mientras que los representantes del sector minero en general reportaron una mayoría de respuestas centradas en sus organizaciones, los habitantes de Cucurpe en particular reportaron no creer que el cambio climático afectaría a la mina de su localidad porque tiene suficientes recursos para adaptarse, y tampoco consideraron que las respuestas de la mina (sobre todo aquellas relacionadas con el agua) pudieran afectar a su comunidad, dado que hasta ahora no han tenido problemas. Antes bien, existe otro tipo de amenazas antropogénicas, tales como la laguna municipal de aguas residuales que está aguas arriba de la localidad. No se reconoce, o al menos no de forma explícita, el carácter sistémico del entorno que comparten la mina y la comunidad y sus implicaciones para el acceso a cantidades y calidades suficientes de agua en un contexto de cambio climático.

Mediante el análisis de las respuestas de los habitantes se identificaron varios temas contrastantes entre las ventajas materiales de corto plazo derivadas de la mina y sus riesgos y costos ambientales. Sin embargo, además de que las ventajas materiales no parecen dirigirse a la construcción de capacidades colectivas para responder a los estresores y shocks socio-ambientales, los riesgos ambientales tampoco se prevén, probablemente por referirse a escalas temporales y espaciales distintas de la vida cotidiana de la comunidad. También se observan efectos profundos de la forma en que se distribuyen en la localidad los recursos y los riesgos, puesto que algunos hogares procuran medios de vida mineros a falta de alternativas de empleo agropecuario, a cambio de asumir riesgos colectivos mayores que podrían agudizarse en un contexto de cambio climático.

Aunque existe incertidumbre sobre el futuro de la seguridad hídrica local, se reconoce que las afectaciones son multifactoriales. Por ejemplo, los riesgos de contaminación del agua pueden incrementarse por la variabilidad climática 
y la presencia minera, pero también por la incapacidad de gestión institucional para mejorar la infraestructura y los servicios municipales.

Una limitación del estudio que podría solventarse en el futuro es aumentar la muestra de participantes y comunidades mineras para el estudio de la minería, seguridad hídrica y cambio climático, así como ampliar el marco temporal del análisis. Esto permitiría tener una imagen más detallada de lo que ocurre en el estado y mejorar la representatividad y la capacidad de generalización de los hallazgos, así como observar mejor el desarrollo de estresores, respuestas y resultados de los procesos de cambio global contemplados en el MDE. Esto es importante sobre todo para el noroeste de México y para Sonora, que es uno de los mayores centros mineros del país y uno de sus mayores focos rojos de cambio climático.

\section{Referencias}

Aburto, O., Rojo, J., y Ezcurra, E. (2015). Los impactos de la minería de oro: repensando una minería sustentable. La Jornada Ecológica, 2015 (200) (especial). Recuperado de https://www.jornada.com.mx/2015/07/27/eco-c. html

Agrawal, A., y Perrin, N. (2008). Climate adaptation, local institutions, and rural livelihoods. IFRI Working Paper No. W081-6. Michigan: International Forestry Resources and Institutions Program.

Bracamonte Sierra, A., Lara Enríquez, B. E., y Borbón Almada, M. I. (1997). El desarrollo de la industria minera sonorense: el retorno a la producción de metales preciosos. región y sociedad, 8(13-14), 39-75. doi: https://doi. org/10.22198/rys.1997.13-14.a1136

CartoCrítica y Heinrich Böll Stiftung. (2016). Concesiones de agua para las mineras. Recuperado de https://cartocritica.org.mx/2016/concesiones-de-agua-para-las-mineras/

Comisión Nacional del Agua (CONAGUA). (2019). Registro público de derechos de agua (REPDA). Base de datos en línea. Recuperado de https://app.conagua.gob.mx/Repda.aspx

Comisión Nacional del Agua (CONAGUA). (2015a). Disponibilidad de agua por acuífero (shapefile). Recuperado de https://www.datos.gob.mx/busca/dataset/disponibilidad-de-agua-subterranea-de-conagua

Comisión Nacional del Agua (CONAGUA). (2015b). Cuencas hidrológicas que cuentan con reserva (shapefile). Recuperado de https://www.datos.gob. mx/busca/dataset/reservas-de-aguas-nacionales-superficiales-de-conagua

Comisión Nacional del Agua (CONAGUA). (2014). Vedas, Reservas y Reglamentos de Aguas Nacionales Superficiales. Recuperado de https: / / www.gob.mx/conagua/documentos/vedas-reservas-y-reglamentos-de-aguas-nacionales-superficiales

Díaz Caravantes, R., Duarte Tagles, H., y Durazo, F. M. (2016). Amenazas para la salud en el río Sonora: análisis exploratorio de la calidad del agua reportada 
en la base de datos oficial de México. Revista de la Universidad Industrial de Santander. Salud, 48(1), 91-96.

Grothmann, T., y Patt, A. (2005). Adaptive capacity and human cognition: the process of individual adaptation to climate change. Global Environmental Change, 15(3), 199-213. doi: 10.1016/j.gloenvcha.2005.01.002

Instituto Nacional de Estadística y Geografía. (2015). México en cifras / Sonora / Cucurpe, 2015. Recuperado de https://www.inegi.org.mx/app/areasgeograficas/?ag=26\#

Intergovernmental Panel on Climate Change (IPCC). (2014). Synthesis Report. Contribution of Working Groups I, II and III to the Fifth Assessment Report of the Intergovernmental Panel on Climate Change (edited by the Core Writing Team, Pachauri, R. K., Meyer, L.A.). Ginebra: IPCC.

Kotsadam, A., y Tolonen, A. (2016). African mining, gender, and local employment. World Development, 83, 325-339. doi: https://doi.org/10.1016/j. worlddev.2016.01.007

Leichenko, R., y O’Brien, K. (2008). Environmental change and globalization. Double exposures. Nueva York: Oxford University Press.

Loayza, N., y Rigolini, J. (2016). The local impact of mining on poverty and inequality: evidence from the commodity boom in Peru. World Development, 84, 219-234. doi: https://doi.org/10.1016/j.worlddev.2016.03.005

Lutz Ley, A. N., y Buechler, S. (2020). Mining and women in northwest Mexico: a feminist political ecology approach to impacts on rural livelihoods. Human Geography, 13(1), 74-84. Doi: 10.1177/1942778620910901

Magaña, V. (2006). El cambio climático global, ¿qué significa? En J. Urbina Soria y J. Martínez Fernández (comps.), Más allá del cambio climático: las dimensiones psicosociales del cambio ambiental global (pp. 79-87). México: Instituto Nacional de Ecología y Universidad Nacional Autónoma de México.

Martínez-Austria, P. F., Bandala, E. R., y Patiño-Gómez, C. (2016). Temperature and heat wave trends in northwest Mexico. Physics and Chemistry of the Earth, Parts A/B/C, 91, 20-26. doi: https:/ / doi.org/10.1016/j.pce.2015.07.005 Martínez-Austria, P. F., Patiño-Gómez, C., y Tamayo-Escobar, J. E. (2014). Análisis de tendencias climáticas en la cuenca baja del río Yaqui, Sonora, México. Tecnología y Ciencias del Agua, 5(6), 135-149.

Mateos, E., Santana, J. S., Montero-Martínez, M. J., Deeb, A., y Grunwaldt, A. (2016). Possible climate change evidence in ten Mexican watersheds. Physics and Chemistry of the Earth, Parts A/B/C, 91, 10-19. doi: https://doi. org $/ 10.1016 /$ j.pce.2015.08.009

Monge, C., Patzy, F., y Viale, C. (coords.). (2013). Minería, energía, agua y cambio climático en América Latina. México: Fundación Heinrich-Böll-Stiftung México-Centroamérica-el Caribe.

Montero-Martínez, M. J., Martínez-Jiménez, J., Castillo-Pérez, N. I., y Espinoza-Tamarindo, B. E. (2010). Escenarios climáticos en México proyectados para el siglo XXI: precipitación y temperaturas máxima y mínima. En P. Martínez-Austria y C. Patiño-Gómez (eds.), Atlas de vulnerabilidad hídrica en México ante el cambio climático (pp. 39-63). México: Instituto Mexicano de Tecnología del Agua. 
Navarro Estupiñan, J., Robles Morua, A., Vivoni, E. R., Zepeda, J. E., Montoya, J. A., y Verduzco, V. S. (2018). Observed trends and future projections of extreme heat events in Sonora, Mexico. International Journal of Climatology, 38(14), 5168-5181. doi: https://doi.org/10.1002/joc.5719

Overpeck, J., Garfin, G., Jardine, A., Busch, D. E., Cayan, D., Dettinger, M., Fleishman, E., Gershunov, A., MacDonald, G., Redmond, K. T., Travis, W. R., y Udall, B. (2013). Summary for decision makers. En G. Garfin, A. Jardine, R. Merideth, M. Black, y S. LeRoy (eds.), Assessment of Climate Change in the Southwest United States: A Report Prepared for the National Climate Assessment (pp. 1-20). Washington, D. C.: Island Press.

Premier Gold, Ltd. (2018). Technical Report on the Mercedes Gold-Silver Mine, Sonora State, Mexico. NI 43-101 Report. Toronto: Roscoe Postle Associates Inc. y Premier Gold Ltd.

Romero, F. M., Armienta, M. A., Gutiérrez, M. E., y Villaseñor, G. (2008). Factores geológicos y climáticos que determinan la peligrosidad y el impacto ambiental de los jales mineros. Revista Internacional de Contaminación Ambiental, 24(2), 43-54.

Scott, C. A., Meza, F. J., Varady, R. G., Tiessen, H., McEvoy, J., Garfin, G. M., Wilder, M., Farfan, L. M., Pineda-Pablos, N., y Montana, E. (2013). Water security and adaptive management in the arid Americas. Annals of the Association of American Geographers, 103(2), 280-289. doi: https://doi.org/10. 1080/00045608.2013.754660

Servicio Geológico Mexicano (SGM). (2017). Panorama minero del estado de Sonora. Diciembre 2016. México: Servicio Geológico Mexicano.

Yacoub, C., y Boelens, R. (2015). Despojo del agua en Latinoamérica: introducción a la ecología política del agua en los agronegocios, la minería y las hidroeléctricas. En C. Yacoub, B. Duarte y R. Boelens (eds.), Agua y ecología política. El extractivismo en la agroexportación, la minería y las hidroeléctricas en América Latina (pp. 11-29). Quito: Justicia Hídrica y Abya-Yala Ediciones. 